\title{
QUINTESSENTIAL RISK FACTORS: THEIR ROLE IN PROMOTING COGNITIVE DYSFUNCTION AND ALZHEIMER'S DISEASE
}

\author{
Mak Adam Daulatzai \\ Sleep Disorders Group, \\ The University of Melbourne \\ EEE/MSE, Parkville, Victoria 3010, Australia
}

\begin{abstract}
1. Introduction

2.0 Obstructive Sleep Apnea (OSA)

2.1 OSA - Upper Airway Dysfunction/Collapse

2.2 OSA Causes Hypertension

2.3 OSA Causes Metabolic Disturbances

2.4 OSA Causes Endothelium and Nitric Oxide Pathology

3.0 OSA and Cognitive Decline

4.0 Brainstem Dysfunction

4.1 Nucleus of the Solitary Tract (NTS)

4.2 NTS - Aging, Brain Volume Decrease

4.3 Hypoxic Injury and Neuronal Apoptosis

4.4 NTS and Neuroinflammation
\end{abstract}

5.0 Cerebral Hypoperfusion

5.1 Cerebrovascular Dysfunction in OSA

5.2 Impaired Cerebral Perfusion in OSA

5.3 Impaired Cerebral Blood Flow - Amyloid Beta

5.4 Impaired Glucose Metabolism in OSA

5.5 Impaired Glucose Metabolism in aging/AD

5.6 Insulin Resistance

6.0 Dementia

7.0 Comments

7.1 Concomitant Adverse Factors Enhance Cognitive Pathology

7.2 Hypoxia, Hypertension and Hypoperfusion - Neurocognitive Impairment

7.3 Reconciling with Theories of AD Pathogenesis

7.4 Mitochondrial Dysfunction - OSA and AD

7.5 Hypoxia, Hypertension and Hippocampus - Cognitive Impairment

\subsection{Final Remarks}

8.1 OSA, Obesity, Diabetes and Hypertension:

8.2 Critique of the Current Paradigm

\subsection{Conclusions}

10.0 References 


\section{ABBREVIATIONS}

\begin{tabular}{|c|c|}
\hline AGEs & advanced glucose endproducts \\
\hline AD & Alzheimer's disease \\
\hline$A \beta$ & amyloid- $\beta$ \\
\hline APP & amyloid precursor protein \\
\hline APAP & autotitrating positive airway pressure \\
\hline $\mathrm{AHI}$ & Apnea-hypopnea index - \\
\hline BACE & $\beta$-site amyloid precursor protein cleavage enzyme \\
\hline BFB & basal forebrain \\
\hline BOLD & blood-oxygenation-level-dependent \\
\hline $\mathrm{BP}$ & blood pressure \\
\hline CAA & amyloid angiopathy \\
\hline CBFV & cerebral artery blood flow velocity \\
\hline $\mathrm{CIC}$ & circulating Inflammatory Cytokines \\
\hline $\mathrm{CIH}$ & chronic intermittent hypoxia \\
\hline $\mathrm{CMRO}_{2}$ & cerebral metabolic rate of oxygen \\
\hline cox-2 & cycloxygenase-2 \\
\hline CRP & C-reactive protein \\
\hline CPAP & continuous Positive Airway Pressure \\
\hline DM & type 2 diabetes mellitus \\
\hline DMV & dorsal motor nucleus $\mathrm{V}$ cranial nerve \\
\hline DMNV & dorsal motor nucleus of the vagus \\
\hline EDS & excessive daytime sleepiness \\
\hline ERC & entorhinal cortex \\
\hline GMV & gray matter volume \\
\hline
\end{tabular}




\begin{tabular}{|c|c|}
\hline HEP & high energy phosphates \\
\hline HIF & hypoxia-inducible factor \\
\hline ICAM-1 and -2 & intercellular adhesion molecule- 1 and -2 \\
\hline IGF-1R & IGF-1 receptor \\
\hline $\mathrm{IH}$ & intermittent hypoxia \\
\hline IR & insulin receptor \\
\hline IL-1 $\beta$ & interleukin-1 $\beta$ \\
\hline LDL & low-density lipoprotein \\
\hline MMP & matrix metalloproteinase 2 \\
\hline MTL & medial temporal lobe \\
\hline NMDARs & N-methyl-D-aspartate receptors \\
\hline MCAV & middle cerebral artery velocity \\
\hline $\mathrm{MCl}$ & Mild cognitive impairment \\
\hline NA & nucleus ambiguus \\
\hline NIRS & Near-infrared spectroscopy \\
\hline NFTs & neurofibrillary tangles \\
\hline NO & nitric oxide \\
\hline NREM & non-rapid eye movement sleep \\
\hline$N F-\kappa B$ & nuclear factor kappa B \\
\hline NTS & nucleus of the solitary tract \\
\hline OSA & obstructive sleep apnea \\
\hline PCC & posterior cingulate cortex \\
\hline PECAM & platelet endothelial cell adhesion molecule-1 \\
\hline PFC & prefrontal cortex \\
\hline
\end{tabular}




\begin{tabular}{|c|c|}
\hline RAGE & AGE receptor \\
\hline RAS & renin-angiotensin system \\
\hline ROS & reactive oxygen species \\
\hline SAA & Serum amyloid $A$ \\
\hline SDB & sleep disordered breathing \\
\hline SHR & hypertensive rat \\
\hline SPs & amyloid senile plaques \\
\hline SPECT & single photon emission computed tomography \\
\hline TNF- $\alpha$ & tumor necrosis factor- $\alpha$ \\
\hline UA & upper airway \\
\hline VBM & Voxel-based morphometry \\
\hline VEGF & vascular endothelial growth factor \\
\hline
\end{tabular}




\begin{abstract}
Alzheimer's disease (AD) is a progressive neurodegenerative disorder. The human brain is extremely sensitive to hypoxia, ischemia, and glucose depletion. Impaired delivery of oxygen in obstructive sleep apnea (OSA) alters neuronal homeostasis, induces pathology, and triggers neuronal degeneration/death. This article systematically delineates the steps in the complex cascade leading to $A D$, focusing on pathology caused by chronic intermittent hypoxia, hypertension, brain hypoperfusion, glucose dysmetabolism, and endothelial dysfunction. Hypoxia/hypoxemia underpins several pathological processes including sympathetic activation, chemoreflex activity, neuroinflammation, oxidative stress, and a host of perturbations leading to neurodegeneration. The arterial blood flow reduction in OSA is profound, being about $76 \%$ in obstructive hypopneas and $80 \%$ in obstructive apneas; this leads to cerebral ischemia promoting neuronal apoptosis in neocortex and brainstem. OSA pathology also includes gray matter loss in the frontal, parietal, temporal, and occipital cortices, the thalamus, hippocampus, and key brainstem nuclei including the nucleus tractus solitarius. (18)F-FDG PET studies on OSA and AD patients, and animal models of $A D$, have shown reduced cerebral glucose metabolism in the above mentioned brain regions. Owing to the pathological impact of hypoxia, hypertension, hypoperfusion and impaired glucose metabolism, the adverse cardiovascular, neurocirculatory and metabolic consequences upregulate amyloid beta generation and tau phosphorylation, and lead to memory/cognitive impairment - culminating in $A D$. The framework encompassing these factors provides a pragmatic neuropathological approach to explain onset of Alzheimer's dementia. The basic tenets of the current paradigm should influence the design of therapeutic strategies to ameliorate AD.
\end{abstract}

Key words: Alzheimer's disease, amyloid- $\beta$, obstructive sleep apnea, hypoxia, hypoxemia, hypertension, neuroinflammation, cerebral hypoperfusion, nucleus of the solitary tract 


\subsection{Introduction}

Late onset Alzheimer's disease $(A D)$ is a progressive neurodegenerative disorder which is characterized by increasing impairment in memory, cognition and emotional processes. AD is the major cause of dementia in the middle- to-old aged individuals. Although old age is the most important risk factor for $A D, 90 \%$ of people over 65 have no clinical dementia. Despite significant advances in understanding $A D$ over the past 30 years, there are major gaps in our knowledge of etiopathology. The major pathological hallmarks of $A D$ are extracellular amyloid- $\beta(A \beta)$ plaques and intraneuronal neurofibrillary tangles (NFTs) composed of hyperphosphorylated tau protein. Neurodegeneration in $A D$ is an ongoing pathologic condition in which neuronal cells degenerate in various key areas of the brain such as brainstem, hippocampus, and basal forebrain - to name a few. The core neuropathological processes underlying AD are accumulation of excess amyloid plaques and formation of neurofibrillary tangles. Further, progressive cerebral atrophy, cognitive decline, and the relentless progression of neurodegeneration ultimately leads to death.

$A \beta$ is the cleaved product of the transmembrane amyloid precursor protein (APP). APP is cleaved by $\beta$-secretase (also called BACE, $\beta$-site amyloid precursor protein cleavage enzyme) and subsequently by the $\gamma$-secretase complex producing two $A \beta$ isoforms, viz. $A \beta-40$ and $A \beta-42$; both possess neurotoxic potential [1]. Autopsied brains of over 65 year old individuals, without clinical dementia, contain fewer amyloid senile plaques (SPs) and NFTs in the hippocampus and entorhinal cortex. This suggests that formation of SPs and NFTs is part of the normal aging process. However, the brains of demented people contain more SPs and NFTs, not only in the limbic cortex but also elsewhere in neocortex and other brain regions [2]. The more numerous and widespread the SPs and NFTs, the more severe is the dementia. The occurrence of AD pathology in nondemented older persons underscores that the pathophysiological abnormalities that cause $A D$ are set in motion decades prior to cognitive dysfunction/dementia. The underlying pathogenic process may advance rapidly in some individuals causing severe dementia; in others, it may be slow and indolent. Mild cognitive impairment ( $\mathrm{MCl}$ ) is clinically and intrinsically heterogeneous; amnesic $\mathrm{MCl}$ is a clinical state between normal ageing and dementia, these patients having mild $A D$ pathology may progress and convert to full blown AD.

Normal breathing occurs when the collapsible regions of the upper airway (UA) are patent. UA dilator muscles such as genioglossus are phasically active throughout breathing by hypoglossal motor neurons. An obstruction of the UA may occur in adults and children mainly at the level of the pharynx causing obstructive sleep apnea (OSA) [3, 4]. OSA is commonly prevalent - in up to $9 \%$ of middle-aged women and $24 \%$ of middle-aged men [5]. Snoring is employed as a mechanism to prevent the UA obstruction. Unfortunately snoring vibrations, pharyngeal suction collapse, negative pressure, cause pathological perturbations such as 
dysfunctional UA afferent sensory- efferent motor reflex, intermittent hypoxia, and hypoxemia $[3,4,6$,$] . Polysomnography is employed in the evaluation of OSA and apnea-hypopnea index$ (AHI) determines the level of pathology. The frequency and hierarchy of occurrence of oxygen desaturation, EEG arousal and heart rate changes have been determined as immediate consequences of apnea in OSA patients. Of apneas, $78 \%$ caused desaturation, $63 \%$ arousal, and $73 \%$ heart rate increase. Of hypopneas, $54 \%$ caused desaturation, $47 \%$ arousal, and $55 \%$ heart rate increase. Of events with mildest patency reduction $25 \%$ caused desaturation, $42 \%$ arousal, and $42 \%$ heart rate increase. These deleterious effects may overlap but do not occur hierarchically; each may occur alone and in all combinations" [7]. Hence, the clinical outcome and different aspects of the above pathology are based on the quality and quantity of apneas and hypopneas in individual OSA patients [7].

The recurrent UA collapse during sleep is associated with significant morbidity and mortality owing to sympathetic tone perturbations, oxidative stress, inflammation and endothelial dysfunction [8-11]. The hemodynamic and autonomic perturbations that arise in OSA are ascribed to intermittent hypoxia/hypoxemia and repeated arousals; these have been shown to cause hypertension, and a host of other disturbances including cognitive decline. Aging is associated with a decrease in sleep; however, sleep disordered breathing (SDB) may further disrupt sleep in older subjects. Obstructive, central or mixed sleep apneas occur commonly in the elderly, and the prevalence increases with age. Further, OSA has been associated with significant morbidity and an increase in mortality. Patients with $A D$ and OSA experience extensive disruption in sleep. In $A D$, SDB severity is correlated with the degree of cognitive impairment [12]. OSA is a recognized cause of cognitive impairment and diverse concomitantly occurring adverse factors might aggravate cognitive deficits in OSA/AD. It is believed that OSA shares common risk factors with $A D$ and may promote the neuropathogenesis of $A D$ [13]. Hypertension and $A D$ share several pathophysiological risks including the renin-angiotensin system, neuroinflammation [11], early signs of atherosclerosis [14], ischemia, and impaired glucose metabolism [15].

Epidemiological, clinical, and pharmacotherapeutic studies in the extant literature emphasize the commonality of risk factors such as hypertension and type 2 diabetes mellitus (DM) in cardiovascular conditions and AD. In order to explain the underlying neuropathology in $A D$, these studies need to be carefully reevaluated, interpreted, and inter-linked. This effort will then be beneficial to streamline and improve the current treatment, and to develop future therapies for $A D$. The current paper delineates the role of intermittent apnea and hypertension, and their impact on the CNS including the neocortex and the key nuclei of brainstem, e.g. nucleus of the solitary tract (NTS). This is followed in tandem by delineation of the cerebral hypoperfusion and inter-related pathology of attenuated glucose metabolism in OSA and AD. Here 
neurodegeneration is meant to imply apoptosis/degeneration of neurons and cells in their immediate milieu, and attenuation of neurological pathways, as a function of several stigmata discussed here. The inter-related pathophysiological mechanisms and their global CNS impact are considered pivotal in the generation of SPs and NFTs, that lead to neuropathogenesis, cognitive decline, and dementia.

The goal of this review is to dissect the evidence of possible involvement of salient physiological abnormalities in triggering pathological cascade of cognitive decline/AD. Hence, systematic unbiased synthesis is presented of current evidence on the neuropathological profile of AD. A number of Pathological alterations identified include hypoxia, hypoxemia, and neurochemical changes, inflammation, vascular pathologies, oxidative stress, mitochondrial changes, cerebral ischemia and glucose hypometabolism, synaptic dysfunction, neuronal injury, disturbed protein metabolism including plaque and tangle formation, and disrupted metabolic homeostasis. It is evident, therefore, that $A D$ is complex and transcends a single framework. Determining which of the above factors primarily drive neurodegeneration and dementia and which are secondary attributes still requires further research. AD pathogenesis and progression delineated here by a matrix of factors raises the proposition that $A D$ is not a single entity, and should be considered as a syndrome.

\subsection{Apnea (Hypoxia)}

\subsection{OSA - Upper Airway Dysfunction/Collapse}

OSA is a common sleep-disordered breathing condition; it is readily diagnosed and is treatable. About 20 million Americans have OSA, a prevalence which is on an increase. Risk factors include age, male gender, obesity, diabetes, hypertension, and lipid abnormalities. OSA is typically associated with snoring and daytime sleepiness, and is characterized by intermittent episodes of partial or complete obstruction of the UA during sleep that disrupts normal ventilation. This causes recurrent nocturnal arousals. It frequently coexists undiagnosed in patients with cardiovascular disease. The UA function and activity of its dilator muscles are influenced by several factors that include sleep-wake state, anesthesia, lung volume, $\mathrm{Pa}_{\mathrm{O} 2}, \mathrm{~Pa}_{\mathrm{CO} 2}$, hormones, as well as sensory reflex arising from the UA $[6,16]$. In OSA, the UA is vulnerable to collapse during sleep owing to sleep-related decrements in UA dilator muscle activity. This failure of the pharyngeal dilator muscles, such as genioglossus, to oppose the collapsing pressure of the pharynx promotes recurrent episodic apnea causing intermittent hypoxia $(\mathrm{IH})$. Recurrent nocturnal arousals occur in OSA to overcome the UA obstruction and this causes sleep fragmentation. Further, hypoxemia and hypercapnia activate chemoreflexes [16]. 
OSA causes daytime neurocognitive dysfunction owing to physiological alterations in brain [17-19]. In rodents, chronic exposure to IH during sleep, which models the hypoxia/reoxygenation pattern observed in OSA patients, replicates many of the neurocognitive features noted in human OSA, such as learning and memory deficits and impaired vigilance [20]. Exposure to experimentally-induced $\mathrm{IH}$ in the rodent is also associated with age-related neurodegenerative changes and alterations in neurotransmitter systems involved in learning and memory, attention, and locomotor activity [20]. Multiple pathophysiological processes may be involved in the behavioral dysfunction and cognitive susceptibility to $\mathrm{IH}$; such heterogeneous pathways may include increased oxidative stress, inflammation, altered gene regulation, and decreases in synaptic plasticity/dysfunction.

\subsection{OSA Causes Hypertension}

Hypertension is estimated to affect $25 \%$ of the general population with about $50 \%$ of 70 years-old suffer from it [21]. A substantial body of literature has repeatedly shown a potential link between OSA and hypertension. When healthy humans were exposed to 4 days of $\mathrm{IH}$, mean arterial pressure increased, NO derivatives were reduced by $55 \%$, and the cerebral vascularresistance-response (pressor response) to hypoxia increased. This reflects that IH may alter BP and cerebrovascular regulation, and has the propensity to induce cardiovascular and cerebrovascular diseases [22-24]. Indeed OSA has been associated with cardiac failure, myocardial infarction and stroke. Several epidemiologic investigations have emphasized these vascular risks in OSA [25-27]. Compared with carefully matched controls for $\mathrm{AHI}<5$, age and $\mathrm{BMI}$, male OSA patients with $\mathrm{AHI}>15$ showed important metabolic changes predisposing them to vascular disease. Importantly, these metabolic alterations occurred in the absence of identifiable vascular diseases or other disorders that predispose to vascular disease, such as diabetes [27]. Hypertension is a direct consequence of OSA, and the underlying pathophysiological mechanisms may involve brief intermittent elevation of blood pressure (BP) causing sustained systemic hypertension (see below) (Fig. 1). CPAP therapy has been shown to ameliorate sympathovagal imbalance, the brachial-ankle pulse wave velocity, heart rate variability, baroreceptor sensitivity, plasma level of C-reactive protein (CRP), and endothelial function [28]. However, CPAP or APAP treatments may ameliorate sympathetic activity, and lower BP in OSA patients [29-32]. Interestingly, CPAP therapy withdrawal for one week resulted in an immediate return of OSA and a marked increase in sympathetic activity [33].

A majority of OSA patients suffer from hypertension. Human studies reveal activation of sympathetic nerves, endothelial damage, and exaggerated pressor responses to sympathetic neurotransmitters and endothelin. The development of hypertension in OSA patients is multifactorial. IH is implicated in the pathogenesis of hypertension in OSA through mechanisms 
that activate the renin-angiotensin system (RAS) [34]. A direct sympathetic activation of vascular smooth muscle via catecholamine and/or increased production of endothelin 1 (a potent vasoconstrictor) may be involved in the pathogenesis of hypertension in OSA [35, 36]. The release of catecholamines into the circulation may contribute to increases in BP in the short term [37]. In the long term, however, there may be downregulation of adrenergic receptors [38]. Several randomized controlled trials have provided evidence that CPAP therapy reduces $24 \mathrm{~h}$ catecholamine excretion, consistent with a reduction in sympathetic nerve activity [29, 37]. In animal studies $\mathrm{IH}$ leads to chemoreceptor stimulation, sympathetic nerve activity, endothelial damage, and impaired BP modulation. Animal models have shown that the hypertensive effect of OSA is provoked by an intact sympathetic nervous system and an intact carotid chemoreceptor reflex. The RAS may be a central player in evoking hypertension in OSA, because renal nerve denervation, angiotensin II receptor blockade, and suppression of the RAS - all prevent the rise in BP [39]. Although treatment of OSA normalizes sympathetic nerve responses, it lowers BP only modestly $[31,40]$.

Various studies have implicated the microvasculature inflammation in the brainstem, specifically in the NTS in the pathogenesis of hypertension [41, 42]. The inflammatory signaling molecules released from the brainstem microvasculature may exert deleterious effects on neuronal excitability in the NTS; this may exacerbate baroreflex inhibition of cardiac sympathetic outflow and alter both the central set point of arterial pressure and its reflex control [43]. Experimental lesion of the NTS leads to loss of baroreflex control of blood pressure, sympathetic activation, and severe hypertension [44]. OSA-related hypertension is correlated with changes in the baroreceptor reflex. Owing to pharyngeal collapse in OSA, changes in inspiratory resistance and in inspiratory oxygen and carbon dioxide content cause changes in the gain or setting of the carotid baroreflex. This leads to an increase in BP, and thus provides a mechanism linking OSA to hypertension [45].

Cerebral autoregulation is a tightly controlled mechanism to maintain a relatively constant blood flow during fluctuations in its perfusion pressure. Its measure is cerebral artery blood flow velocity (CBFV). OSA patients possess decreased CBFV and delayed cerebrovascular compensatory response to changes in $\mathrm{BP}$ [46]. A dose-response relationship exists between the severity of OSA and the development of mean BP. Hence OSA is a disorder with evidence of cerebrovascular and structural cerebral lesions [47]. Patients with moderate to severe OSA (apnea-hypopnea index $-\mathrm{AHI}>$ or $=15 / \mathrm{h}$ ) may have a high prevalence of silent cerebrovascular lesions [48]. In one cohort, the incidence of lacunar infarction was $48.6 \%$ in moderate OSA and $54.0 \%$ in severe OSA (compared with controls) $[48,49]$. Recent data on a cohort of 686 older nondemented adults from a northern Manhattan community (Washington Heights-Linwood 
Columbia Aging Project) showed increased frequency of infarction in high BP groups, but low frequency in low BP [49]. This further emphasizes the importance of subclinical ennin ng cular disease in the hypertensive elderly.

Various vascular, inflammatory, and neural abnormalities evident in OSA are implicated in the pathogenesis of diverse cardiovascular disease conditions. The deleterious impact of OSA includes the sympathetic-mediated vasoconstriction that has hemodynamic consequences leading to increases in systemic and pulmonary pressure, increased left ventricular (LV) afterload, and breathing-related changes in cardiac output [50]. Owing to increased chemoreflex drive, OSA patients have high levels of sympathetic nerve drive to blood vessels, even when awake and normoxic during daytime [50,51]. The generation of reactive oxygen species (ROS) in OSA, and the comorbid conditions like DM and obesity might further promote cardiovascular morbidity. An increase in ROS can upregulate vascular adhesion molecules, cause platelet aggregation, and decrease the vasodilator NO. OSA with hypertension can deteriorate into life-threatening cerebral hypoxemia, encephalopathy, cardiopulmonary arrest and indeed death [52, 53]. Some important OSA-related pathologies encompassing inflammation, cardiovascular disease(s) and endothelial dysfunction are described below.

\subsection{OSA Causes Metabolic Disturbances}

Oxyhemoglobin as well as brain activity are known to decrease during OSA [54]. Hypoxia and inflammation are intertwined. Since hypoxia can induce inflammation, inflamed lesions often become severely hypoxic, with increased metabolic demands. Further, vascular leakage, accumulations of inflammatory cells, and elevated serum levels of cytokines have been shown in mice after short-term exposure to low oxygen concentrations [55-57]. The dynamic perturbations in brain oxygen partial pressure in response to intermittent hypoxia decrease brain's buffering capacity of high energy phosphates (HEP). Thus in OSA, the creatine kinase system may be dysfunctional and the ennin ng cular compensatory mechanisms may be inadequate to prevent decrements in HEP [58]. A recent study has shown that the serum low-density lipoprotein cholesterol (LDL-C)/high-density lipoprotein cholesterol (HDL-C) correlated positively with apnea-hypopnea index, and negatively with the lowest arterial oxyhemoglobin saturation. Further, the $\mathrm{AHI}$ or the lowest arterial oxyhemoglobin saturation was independently associated with LDL-C/HDL-C [59]. Therefore, the LDL-C/HDL-C increases in proportion to the OSA severity, and its significant reduction after CPAP therapy clearly highlights that intermittent apnea/hypoxia is an enormously important adverse mechanism contributing to an increased risk for cardiovascular events in OSA patients. When apolipoprotein E-deficient mice were subjected to intermittent hypoxia, there was a progressive increase in BP, which is reflective of arterial stiffness [60]. Chronic intermittent hypoxia $(\mathrm{CIH})$ upregulated the lipoprotein secretion enzyme 
stearoyl coenzyme A desaturase 1 (SCD-1) in OSA patients; they exhibited oxyhemoglobin desaturation, higher plasma triglyceride and low-density lipoprotein cholesterol levels (compared to control normoxics) [61]. Similarly, hypoxemic mice too showed increased SCD-1, dyslipidemia, and atherosclerosis [61]. The literature is rife with studies on the role of OSA/hypertension in several proatherogenic effects including systemic inflammation, dyslipidemia, lipid peroxidation, oxidative stress, vascular smooth cell activation, increased adhesion molecule expression, monocyte/lymphocyte activation, increased lipid loading in macrophages, and endothelial dysfunction [62].

Metabolic alterations in OSA may include higher levels of insulin resistance, serum leptin, urinary norepinephrine excretion, and a reduction in serum IGF-I levels, to name a few. Multiple linear regression with OSA as a predictor (controlling for waist circumference, age, and alcohol consumption) has confirmed an independent association between OSA and the above mentioned metabolic risks [27]. Hypoxia may induce insulin resistance by producing ROS and inflammatory cytokines. There is copious literature documenting the role of hypoxia in inducing synthesis of proinflammatory cytokines [63-71]. Consequently, there is evidence of a low-grade chronic subclinical indolent upregulation of inflammatory state by elevated levels of interleukin 6 (IL-6), tumor necrosis factor a (TNF- $\alpha$ ), CRP, NF-KB, ICAM-1, VCAM-1 and E-selectin in OSA [27, 6371]. Hypoxemia and sleep deprivation have a synergistic effect and causes production of proinflammatory cytokines and C-reactive protein in OSA subjects [63, 72, 73]. Elderly subjects showed enhanced plasma D-dimer levels with increased awake time after sleep onset [74, 75]. Plasma levels of von Willebrand's factor, a mediator of platelet adhesion/ coagulation cascade is associated with arousal index [76]. In OSA, inflammation may be an important contributor to endothelial dysfunction. In addition to inflammatory cytokines, CRP may also contribute to vascular dysfunction by inhibiting NO synthase [77] and by increasing cell adhesion, e.g. monocyte, during inflammation [78]. Activation of the above inflammatory mechanisms may impact endothelial function, decrease the production of $\mathrm{NO}$, and result in impaired vasodilation and higher BP. This may suggest that OSA is a predisposing factor for endothelial dysfunction, oxidative stress, inflammation and atherogenesis - all these may play a causative role in neurocognitive dysfunction [79-81]. In the aged, the damage-causing proinflammatory cytokines in the NTS and hypoglossal nucleus may cause UA obstruction/collapse, snoring/apnea, hypoxia, hypertension, and cerebral ischemia. Systemic inflammation has an impact on microglia and switches them to a primed phenotype that synthesizes proinflammatory cytokines in the CNS, more so in the aged OSA [82-84]. Platelets play important roles in several diseases/pathologies including OSA [85, 86] and AD [87]. Following activation, platelets adhere to leukocytes and endothelial cells via p-selectin, platelet endothelial cell adhesion molecule-1 (PECAM), and intercellular adhesion molecule-1 and -2 (ICAM-1 and -2); they secrete phospholipase A2 and 
cycloxygenase-2 (COX-2), as well as other proinflammatory chemokines and interleukins [88]. Further, they are a rich source of intraplatelet $A \beta$ [89].

\subsection{OSA Causes Endothelium and Nitric oxide Pathology}

Dysfunction of vascular endothelium is characterized by reduced vasodilation and enhanced vasoconstriction, prothrombotic, and inflammatory activity, thus impacting the normal homeostatic functions in the blood vessels. Patients with OSA demonstrate endothelial dysfunction in the absence of any manifested vascular disease [80, 90, 91]. Evidence shows that endothelial dysfunction in OSA is associated with alterations in vasculature's elastic properties, increased circulating cell-derived microparticles, and decreased endothelial repair and vascular reactivity. These alterations are correlated with platelet adhesion and aggregation, leukocyteendothelial adhesion, and reduced nitric oxide (NO) (impacting vasodilation). Further, in addition to impact of hypoxia, the endothelial dysfunctions are related to sleep loss and sleep fragmentation, increased levels of angiotensin II, endothelin 1, inflammation, oxidative stress, procoagulants, and thrombotic activity [64, 91, 92, 93]. The above mentioned dysfunctions contribute to the development of hypertension as well as atherosclerosis, obesity, insulin resistance, and cardiovascular disorders. However, the therapeutic CPAP may reverse some of the above changes associated with endothelial dysfunction in OSA patients [71].

Normally, the vascular endothelium releases various vasodilators including NO. NO plays several important roles such as the regulation of vascular tone, inhibition of platelet aggregation, prevention of adhesion of leukocytes, and proliferation of the intima and smooth muscle. Endothelial dysfunction is a critical step in the pathogenesis of cardiovascular dysfunction, by promoting vasospasm and thrombosis. The former is intimately linked with oxidative stress owing to reduced synthesis of $\mathrm{NO}$, inactivation of $\mathrm{NO}$, and/or increased production of superoxide/ROS [80,94]. Oxidative stress is an outcome of imbalance between the activity of endogenous pro-oxidative enzymes (such as NADPH oxidase, xanthine oxidase, or the mitochondrial respiratory chain) and anti-oxidative enzymes (such as superoxide dismutase, glutathione peroxidase, heme oxygenase, thioredoxin peroxidase/peroxiredoxin, and catalase), in favor of the former [94]. Indeed, the bioavailability of NO is modulated by ROS that degrade NO, inhibit its synthesis, and uncouple NO synthase. Recurrent hypoxia/apnea leads to lipid peroxidation and atherosclerosis in the absence of diabetes and obesity, and the degree of these metabolic dysregulation has been shown to be dependent on the severity of the hypoxic stimulus [95].

\subsection{OSA and Cognitive Decline}


Increased oxidative stress and inflammation, altered gene regulation, and decreases in the cellular and molecular substrates of synaptic plasticity are implicated in memory impairment. Exposure to experimentally-induced OSA in the rodent correlates with age-related neurodegenerative changes, alterations in brain regions, and neurotransmitter systems involved in learning, memory, and attention [20]. As well as impacting several metabolic and humoral functions (described above), OSA adversely impacts CNS structure/function also. The higher $\mathrm{AHI}$ has a significant negative association with the degree of metabolic impairment in cerebral white matter, independent of age and the presence or absence of cardiac disease [96]. Neuroimaging has provided invaluable data on regional gray and white matter losses in aging [97] and OSA [11,98]. The performance of OSA patients is poor on neuropsychological tests including complex attention, executive function, and psychomotor speed. Executive functions are the most affected cognitive elements in OSA in that some OSA patients had mild dysfunction (2.5-12.5\%) and others severe (5-15\%) [99]. Performance on a battery of 10 cognitive tests showed that constructive ability, deductive thinking and both verbal and immediate memory showed comparable impairment in patients with OSA, and mild-moderate AD [100].

As emphasized above, vascular disease is an important risk factor for AD. Neuropsychologic tests in pretreatment OSA patients showed impairments in most cognitive areas; these patients have focal reductions of gray matter volume (GMV) in the left hippocampus, entorhinal cortex, left posterior parietal cortex, and right superior frontal gyrus. Voxel-based morphometry (VBM) documented smaller GMV in right and left hippocampus, right and left caudate, and within more lateral temporal areas were in OSA patients (compared to controls) after controlling for comorbidities including hypertension, diabetes, smoking, and hypercholesterolemia [101]. Patients with OSA demonstrate significant reduction in working memory; they perform poorly on neuropsychological measures of attention, executive decision, and psychomotor speed. A comparison of pre- and post-treatment neuropsychological test scores, after 3 weeks of therapeutic CPAP in OSA patients showed a significant improvement in cognition [102]. Following CPAP therapy (to ameliorate oxygen desaturation in OSA), OSA subjects regain increased alertness; they improve neurobehavioral outcomes in cognitive processing, memory, and executive function [103]. In a recent study, CPAP treatment results in improvements in memory, attention, executive-functioning, and GMV increase in hippocampus and frontal cortex [104]. Other data in contrast have demonstrated that despite long-term CPAP treatment some cognitive deficits still remain resistant to treatment [105].

\subsection{Brainstem Dysfunction}

\subsection{Nucleus of the Solitary Tract (NTS)}


The nucleus of the solitary tract (NTS) is a compact network of neurons located in the dorsal brainstem. The NTS is an important brainstem nucleus where "initial integration" occurs of a wide variety of sensory inputs from gustatory, gastrointestinal, cardiovascular, and respiratory (from both upper and lower airway) systems, to name a few. The second-order NTS neurons integrate the sensory information spatially and temporally, with inputs from local networks, higher brain regions, and circulating mediators, and orchestrate an efferent output [106]. The NTS neurons integrate the incoming sensory information and transmit it to the dorsal motor nucleus of cranial nerve $\mathrm{V}$ (DMV). In addition, the NTS provides extensive efferent signals to the parabrachial, DMV, nucleus ennin ng (NA), locus coeruleus, and the hypoglossal, and the parasympathetic preganglionic neurons - to name a few. It is here in the NTS that the afferent and efferent pathways of the parasympathetic nervous system meet [107]. Furthermore, the NTS has direct and indirect connections to a wide range of neural structures in the CNS, thus possessing the propensity to affect a broad array of neurophysiological pathways [17-19,108].

\subsection{Aging, Brain Volume Decrease and NTS}

Scans of whole brain GMV using MRI morphometry did not differ significantly between subjects with and without OSA; however, bilaterally, a significant inverse relationship was found between AHI and GMV in the (1) NTS, (2) Nucleus Ambiguus, and (3) the Dorsal Motor Nucleus of the vagus (DMNV) [109]. The symmetrical atrophy of these key brainstem nuclei was interpreted as a function of intermittent hypoxic and sleep disturbances. The above specific brainstem nuclear GMV loss in asymptomatic OSA subjects reflects an ongoing silent pathophysiological change in the elderly with sleep disordered breathing. In addition to subclinical breathing abnormalities during sleep, other abnormalities the elderly could possibly suffer from are subclinical ongoing decreases in olfactory, gustatory, and somatosensory modalities of senescence $[4,6,110]$, as well as they may be subjected to the effects of episodic variable bacterial/viral infections, and consumption of alcohol and other chemicals (medications) [17-19]. The above mentioned may have an additive adverse impact decreasing the NTS function and its volume $[17,18]$. This may conceivably result in: NTS dysfunction $\rightarrow$ decrease in genioglossus activity $\rightarrow$ decrease in the pharyngeal patency $\rightarrow$ causing intermittent apnea/snoring, hypoxia/hypoxemia during sleep, and their widespread adverse effects described before.

\subsection{NTS: Hypoxic Injury and Neuronal Apoptosis}

Several studies show that cortical and brainstem neurons are vulnerable to hypoxia. Hypoxia decreases spontaneous activity in more than two-thirds of neurons recorded in vitro in the rat NTS [111]. In all neurons tested, hypoxia decreased synaptic potentials of the NTS [111]. In vivo, $\mathrm{ClH}$ induces a reduction in evoked synaptic transmission between sensory afferents and 
NTS second-order cells [112]. Following OSA, a large number of apoptotic neurons were present in the ennin $\mathrm{ng}$, insular and frontal cortices, the hippocampus and the ennin $\mathrm{n}$ (compared to control guinea pigs) [113]. Levels of vascular endothelial growth factor (VEGF), NO, and glutamate were significantly increased in brainstem tissue (over control levels) after hypoxic injury. Swollen neurons and dendrites, degenerating axons, disrupted myelin sheaths, and swollen astrocyte processes were observed in the apneic adult rat NTS [114]. Subjecting mice to $\mathrm{CIH}$ induces caspase-3 activation and cortical neuronal cell apoptosis [115].

The NTS neurons are highly vulnerable to ischemia also. Hypoxic-ischemic injury of the piglet brain showed that their medulla had widespread distribution of apoptosis in different brainstem nuclei, including the NTS [116]. Hypoxic-ischemic injury was found to significantly reduce numbers of catecholaminergic neurons in the locus coeruleus and the NTS of the rat [117]. Using an animal model of sleep apnea, it was determined that the degeneration of neurons and glia, due to apoptosis, occurs in specific regions of the pons and medulla in adult guinea pigs. These regions included nuclei of cardiovascular functions viz. the nucleus ennin $\mathrm{ng}$, the NTS and the dorsal motor nucleus of the vagus (DMNV), as well as the dorsal raphe and locus coeruleus [118]. Apoptosis ascribed to hypoxic-ischemic injury was studied in human brainstems (taken at autopsy from 15 adults; age range: 25-58 years); the apoptotic index in the NTS was about $8.5 \%$, [119]. Shortly after ischemic death (range of survival 10 hours to 2 days), there was widespread bilateral neuronal death in the NTS, while such lesions in other medullary and pontine nuclei were absent [120]. The hypoxia/reoxygenation-induced ROS production may overwhelm antioxidant capacity, and contribute to the neuronal apoptosis [121]. The deleterious effects of hypoxia and ischemia leading to impairments of respiratory, cardiovascular, and neurocognitive functions are associated with substantial cortical and brainstem damage. Such widespread pathology is bound to be pivotal in causing cognitive dysfunction, since the NTS is reciprocally interconnected with almost the entire CNS including the prefrontal cortex, amygdale and the hippocampus. Hence, a dysfunctional NTS may have significant deleterious impact and cause severe neuropsychiatric and memory dysfunction in the aged pathological brain. This is posited to be quite crucial in promoting the neuropathogenetic cascade promoting the onset of cognitive decline/AD dementia.

\subsection{Neuroinflammation and NTS}

Extensive literature exists that emphasizes the importance of neuroinflammation in the pathogenesis of $\operatorname{AD}[122,123]$. As a normal homeostatic mechanism, CNS microglia encapsulates deleterious foci to protect the CNS tissue (by removing apoptotic cells and debris). In chronic neurodegenerative disorders such as AD there is attenuation of astroglial function, and 
activated microglia and macrophages become strongly pro-inflammatory phenotype; they then synthesize potentially neurotoxic proinflammatory cytokines including TNF- $\alpha$ and IL1- $\beta$, as well as ROS and proteolytic enzymes [124]. There is evidence that blood-borne circulating Inflammatory Cytokines $(\mathrm{CIC})$ can influence central neuronal function directly and stimulate local synthesis of

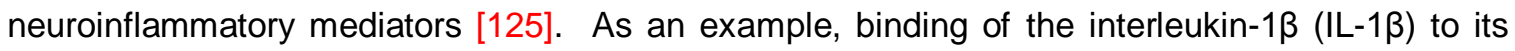
receptors on the neuronal membrane may initiate signaling cascades upregulating transcription of genes including those of COX-2, tumor necrosis factor- $\alpha$ (TNF- $\alpha$ ), and IL-6, and other mediators; these then recruit leukocytes and macrophages that in turn release additional inflammatory cytokines [126]. This central inflammatory response due to peripheral CIC impacts both neocortex and brainstem, and their function. Several reports document pathological features in the NTS when exposed to hypoxia. CIH increased TNF- $\alpha$ and IL-1 $\beta$ production in carotid body and the NTS neurons; the enhanced carotid chemosensory and ventilatory hypoxic responses were implicated in the onset and progression of hypertension [127]. This suggests that proinflammatory cytokines may contribute to the $\mathrm{CIH}$-induced cardiorespiratory alterations, acting at several levels of the hypoxic chemoreflex and cardiovascular control pathways [127].

Hypoxia and/or ischemia stimulates the expression of proinflammatory cytokines (e.g. TNF- $\alpha$, IL-1 $\beta$ ), chemokines (e.g. IL-8, MCP-1/CCL2) and adhesion molecules (e.g. ICAM-1) in the brain and in cultured human and mouse astrocytes and brain endothelial cells [128-133]. Hypoxia upregulates inflammatory genes via several transcription factors including NFKB, activator protein-1, and hypoxia-inducible factor (HIF-1) [128,129,133]. HIF-1 is an essential molecule that regulates oxygen homeostasis and mediates hypoxia-induced expression of IL-1 $\beta$ in astrocytes [134]. Astroglial cells are the most abundant cells in the brain and play an important role in the initiation and progression of hypoxia-induced neuroinflammation [128-132]. OSA subjects suffer from arousals from sleep that enhances sympathetic activity; however, in addition, age-related oxidative stress may also promote vascular inflammation [133]. Recent experimental data suggest that ROS and multiple proinflammatory pathways may converge on NF-kB to enhance its transcriptional activity, and induce endothelial activation in vasculature of the elderly [133]. Cerebral amyloid deposition has been documented in rats after chronic $\mathrm{IH}$ [135].

High levels of proinflammatory molecules including the gp39 precursor are expressed in the NTS of the hypertensive rat (SHR) $[136,137]$. The gp39 precursor that promotes chemotaxis is homologous to chitinase 3-like protein 1 (also known as human cartilage-gp39 or YKL40). High levels of this molecule are also present in diverse inflammatory conditions including rheumatoid arthritis, glioblastoma, inflammatory bowel disease, atherosclerosis, asthma and indeed AD [17, 18, 138]. Furthermore, gp39 precursor also promotes chemotaxis [139]. Thus up-regulation of gp39 precursor is considered to reflect an inflammatory state that may attenuate blood supply/neuronal activity in persistently inflamed and dysfunctional NTS [136, 137, 140]. It has 
been elegantly shown that vessels within the brainstem of hypertensive animals are inflamed and release ROS and proinflammatory cytokines that may alter neuronal activity in the NTS [136, 137, 140]. The above studies have been recently reviewed [4, 17-19]. Furthermore, the brainstem vascular inflammation could possibly elevate the resistance to blood flow thus causing inadequate perfusion - thus presenting a scenario of sympathetically mediated hypertension in response to inadequate blood supply. Conceivably therefore, a synergistic effect of intermittent hypoxia, inflammation and hypoperfusion may render the NTS neurons dysfunctional. The inflamed and dysfunctional NTS may adversely impact functional integrity of its projected pathways/neurons, and downregulate the interconnected key regions in the brainstem and neocortex such as the hippocampus, entorhinal cortex (ERC), basal forebrain (BFB), locus coeruleus, hypothalamus, prefrontal cortex (PFC) and ennin $n$, among others, and trigger cognitive decline [4, 17-19].

\section{$\underline{5.0 \text { Cerebral Hypoperfusion }}$}

\subsection{Cardiovascular Dysfunction in OSA}

OSA either as an independent risk factor or in synergy with comorbidities can impose adverse effect on the cardiovascular function. As described earlier, patients with OSA have a higher prevalence of hypertension (independent of other known risk factors) [27, 141]. OSA and acute sleep deprivation (even in healthy individuals) are associated with incidence of atrial fibrillation [142], increased p-wave dispersion on electrocardiography - an electrophysiological marker for the prediction of paroxysmal atrial fibrillation [143], and left ventricular hypertrophy [144].

Epidemiologic studies have shown a link between snoring/OSA and myocardial function [144, 145]. Acute and chronic pathophysiological stresses of OSA are considered to predispose to myocardial ischemia. A five-year follow-up of coronary artery disease (CAD) patients with OSA revealed that they have a higher mortality $(38 \%)$ compared with those without OSA (9\%) [146]. Hypoxemia due to intermittent apnea, hypercapnia, and surges in sympathetic activation and BP may provoke myocardial ischemia. Hypertension may cause ischemic heart disease, and hypertension labeled essential hypertension may be secondary to OSA $[65,147]$. OSA patients free of clinically significant CAD may possess nocturnal STsegment changes consistent with myocardial ischemia [148]. ST-segment depression is more frequent in severe OSA or nocturnal angina, both being related to oxygen desaturation [149, 150]. Furthermore, inflammatory cytokines that are abundant in OSA may affect myocardial contractility causing cardiovascular dysfunction [65, 81, 147]. 
Short-duration (3-11 weeks) hypertension in the sheep (a model of hypertension) is associated with significant atrial remodeling characterized by atrial enlargement/dysfunction, interstitial fibrosis, inflammation, slowed conduction, increased effective refractory periods, and greater propensity for atrial fibrillation [151]. Inflammation is an important factor indeed in inducing cardiovascular diseases including myocardial ischemia and heart failure [152]. As referred to above, several factors including hypoxia, hypercapnia, and pressor surges during intermittent apnea are potent stimuli that upregulate the levels of endothelin in OSA and trigger vasoconstriction as well as cardiac changes [35]. Patients with OSA who are free of comorbid cardiac or vascular disease may possess impaired endothelial function [153, 154], which is exacerbated by cigarette smoking [155], hyperlipidemia [156], and diabetes [157]. These important comorbid conditions further enhance cardiovascular risk (as per copious literature). Importantly, OSA itself - i.e. without comorbidities, is an independent risk factor for the development of impaired cardiovascular function [158, 159]. Microvascular endothelial dysfunction due to intermittent apnea/oxidative stress is known to improve with CPAP therapy $[80,160]$. Thus, repetitive hypoxia/reoxygenation in OSA promotes vascular inflammation/remodeling, oxidative stress, and cellular apoptosis [69-71].

\subsection{Impaired Cerebral Perfusion in OSA}

Recurrent and intermittent apneas and hypoxemia during OSA are associated with profound changes in CBF, insufficient cerebral autoregulation, and disturbances of ennin ng cular reactivity [39] (also see above). In hypertensive rats, ischemic lesions develop in a wide variety of brain regions, and this pathology is related to hypertension-induced vascular remodeling and persistent hypoperfusion [161]. In the hypertensive rats, arteries in the relaxed ennin ng cular bed, as well as during hypercapnic vasodilation, possess lower cerebral blood flow (CBF) due mainly to decreased internal radius [162]. Consequently, OSA associated with profound changes in CBF predisposes OSA sufferers to cerebral ischemia and cerebral hypoperfusion [163] (Fig.1). A number of studies have shown an association between hypertension and cerebral hypoperfusion [164, 165, 166]. During stage III/IV non-rapid eye (NREM) sleep, CBF and cerebral metabolism decrease. Hypoxia was associated with a reduction in the middle cerebral artery velocity (MCAV) (as an index of $\mathrm{CBF}$ ) explaining the observed CBF reductions in NREM sleep [167]. Near-infrared spectroscopy (NIRS) documented significantly lower (compared with controls) brain tissue oxygen saturation (SO2) and oxyhemoglobin [O2Hb] [168].

A large body of data implicates OSA in playing a significant role in contributing to or exacerbating cardiovascular disorders including myocardial injury and ischemic heart disease, and mortality $[169,170]$. Ischemic foci characteristically possess hyperplastic, thrombosed, and 
compressed vessels. Ischemic lesions significantly reduce CBF, suggesting that in conjunction with decreased MCAV, OSA/hypertension-induced vascular and myocardial remodeling enhances cerebral hypoperfusion [161, 162]. OSA patients have significantly reduced CBF response (CBFR) to hypoxia; however, treatment of OSA with CPAP increases the CBFR [171]. As referred to before, changes in cerebral blood flow velocity (CBFV) and vascular compliance occur in patients with severe OSA. A loss of vasoreactivity and increased arterial stiffness are manifested by CBF hyporeactivity and cerebral pulse transit time reduction [172, 173]. Both hypoxia and a critical reduction in CBF may damage diverse regions in the brainstem including the NTS (Fig.1). Three tegmental areas have been described in brainstem vascularization: 1. a median area fed by the paramedian arteries, 2 . a middle area that is very small and is fed by the short circumferential arteries for the ala cinerea, and 3. a lateral area fed by the posterior inferior cerebellar artery. Because the NTS is localized at the watershed zone between the terminal branches of these arteries, it is quite vulnerable to compromised CBF and to ischemia, particularly in OSA. There are lesions of neuronal degeneration in the hypoxic NTS [174].

\subsection{Impaired Cerebral Blood Flow - Amyloid Beta}

Several epidemiological data including the 2001 MRC-CFAS England and Wales study, the Nun study, Framingham heart study, and the Viennese study $[175,176,177]$ have emphasized the correlation between hypoperfusion and AD. Vascular lesions are frequently associated with AD. AD patients having single or multiple vascular risk factors (hypertension, $\mathrm{DM}$, hypercholesterolemia) were studied for rCBF deficits using repeated single photon emission computed tomography (SPECT). Compared with single vascular risk factor group, those in the multiple vascular risk category had a greater rate of decline in rCBF and cognition [178]. Vascular and metabolic dysfunctions are key components in the AD pathology, and they share common denominator such as hypertension and oxidative stress. The properties of cerebral microvasculature are altered in $A D$ [179]. Cortical microinfarcts observed in $A D$ brains were correlated with vessels having amyloid angiopathy (CAA). Following cerebral hypoperfusion (12 weeks), CBF decreased by $26 \%$ in CAA model mice (compared with wild-type mice) - and these mice showed accelerated deposition of $A \beta$. In contrast, the mice without hypoperfusion exhibited only low $A \beta$ depositions and no microinfarcts even by 32 weeks of age [180]. This and other studies [181], therefore, consider hypoperfusion- a key event in promoting $A \beta$ deposition. The correlation between hypoperfusion, impaired microvascular function and $A \beta$ accumulation has been repeatedly emphasized in the literature [27, 162, 161, 182-184].

Vascular dysfunction underpins reduced CBF, and a correlation exists between vascular pathology and $A \beta$ deposition [184]. There is evidence that ennin ng cular hypoperfusion leads to increased accumulation of APP (precursor of $A \beta$ ). It upregulates expression of the $A \beta$ peptide and decreases its clearance from brain [185, 186]. Cerebrovascular hypoperfusion 
occurs prior to clinical symptoms of $A D$ and thus represents a parameter that may predict possible cognitive impairment in the future. There are several data to support this assertion. Immunoelectron microscopy showed that chronic ennin ng cular hypoperfusion promotes oligomeric $A \beta$ accumulation in the hippocampus, especially in the axonal terminals, in a timedependent manner. Decreased levels of postsynaptic density-95 (PSD-95) and synaptophysin occurred in the CA1 region of the hippocampus after chronic ennin ng cular hypoperfusion [187]. In young adult rats, it was shown that either cerebral hypoperfusion or cerebral angiopathy alone had significant impact on learning and memory; however, a combined effect of the two dysfunctions significantly impaired spatial learning and memory in these young rats [188]. A recent study has confirmed the occurrence of progressive deficits in spatial memory (via Morris water maze test) of the rats having vascular occlusion [189].

\subsection{Impaired Glucose Metabolism in OSA}

Obesity, insulin resistance, hypertension, and dyslipidemia affect millions of people worldwide, and are associated with an increased risk of cardiovascular disease and DM. Available evidence from humans and animal models (that mimic OSA) documents a robust association between OSA and insulin resistance, glucose intolerance, altered glucose metabolism and the risk of DM, independent of obesity [190-194] (Fig.1). Mechanisms implicated, include chronic intermittent hypoxia, sleep fragmentation and sleep loss that may trigger both vascular and non-vascular inflammation, and other abnormalities delineated above. Healthy young adults submitted to recurrent partial sleep restriction showed marked alterations in their glucose metabolism including decreased insulin sensitivity and glucose tolerance [194]. Further, daytime sleepiness in OSA patients showed association with hyperglycemia and hyperinsulinemia [195]. Hence, treatment of OSA has the potential to improve glucose metabolism and energy balance in these patients.

Several studies have documented that OSA represents a metabolic stress that promotes insulin resistance. Although obesity is a major determinant of insulin resistance, extensive data on $\mathrm{AHI}$ and fasting insulin index unambiguously showed OSA also to be an independent determinant of insulin resistance [190, 196] and impaired glucose metabolism [196, 197, 198, 199, 200]. OSA is independently associated with insulin resistance and glucose intolerance in animals also [201, 202]. Furthermore, an increase in apnea or hypopnea per sleep hour increased the fasting insulin level and HOMA-IR (homeostasis model assessment method insulin resistance) by a factor of about $0.5 \%$ [190]. A cross-sectional analysis of 2149 patients showed that prevalence of DM increased with increasing OSA severity and excessive sleepiness [193]. Severe OSA was found to be independently associated with DM in patients when data were collected using a continuous glucose-monitoring system to measure interstitial glucose 
every 5 minutes during polysomnography in DM and newly diagnosed OSA patients. The measurements repeated after CPAP treatment (41 days) showed that CPAP improved insulin responsiveness, and decreased sleeping glucose levels in DM and OSA patients [203, 204]. Up to $83 \%$ of patients with DM suffer from unrecognized OSA, and increasing severity of OSA is independently associated with poorer glucose control [199]. Increased serum level of advanced glycation end-products (AGE) occur in non-diabetic OSA patients; however, decrease in AGE levels with CPAP therapy supports of a direct relationship between OSA and AGEs [205].

OSA and mild hyperglycemia increase sympathetic tone. This hypersympathetic state may be an important mechanism in part for increased incidence of cardiovascular disease in OSA [206]. Since numerous data show a clear association between OSA and altered glucose metabolism; the underlying pathophysiological mechanisms involved have been studied [15]. Moderate to severe OSA imposes an excessive functional demand on pancreatic beta-cells leading to their secretory dysfunction, and hence glucose dysregulation over time. Two distinct mediators that link sleep apnea with Impaired DM are TNF- $\alpha$ and IL-6 [15]. Intermittent hypoxia may affect glucose metabolism by inducing sympathetic activation, enhancing systemic inflammation, upregulating counter-regulatory hormones and fatty acids, and causing direct pancreatic beta-cell dysfunction [207, 208]. Prospective epidemiologic studies are consistent with a causative role of short sleep/OSA in the increased risk of DM. Further, a decrease in sleep is also associated with a reduction of the satiety factor, leptin, and an increase in the hungerpromoting hormone, ghrelin. Thus, sleep loss causes a dysregulation of the neuroendocrine control of appetite altering the ability of leptin and ghrelin to accurately signal caloric need. The internal misperception of insufficient energy availability may increase activity of orexins that promote both waking and feeding, causing higher body mass index [209]. Evidence shows that effective CPAP therapy has a favorable effect on glucose metabolism and improves glycemic control in OSA-DM patients [195, 204, 210, 211]. Indeed, patients with AD and OSA may experience significant improvements in sleep, mood and cognition after CPAP treatment [102].

\subsection{Impaired Glucose Metabolism in Aging and AD}

Glucose homeostasis is an essential pre-requisite for neuronal energy, maintenance, survival, neurogenesis, neurotransmitter regulation, and indeed synaptic plasticity. Normally, the status of glucose/energy metabolism correlates with the level of functional activity, in the structural components of the brain. Functional demands stimulate the rate of glucose utilization, and reduced functional activity depresses it. In gray and white matter regions CBF, CBV, and cerebral metabolic rate of oxygen $\left(\mathrm{CMRO}_{2}\right)$ decrease with age approximately $0.50 \%$ per year; this leads to diminished neuronal firing or decreased dendritic synaptic density [212]. The results of magnetic resonance imaging (fMRI) from a study of episodic memory demonstrated a 
significant reduction in resting-state $\mathrm{CBF}$ and blood-oxygenation-level-dependent (BOLD) response in the medial temporal lobe (MTL) in older (compared to younger) adults [213]. Using positron emission tomography (PET), CMR $\mathrm{O}_{2}$ was measured in healthy aged persons; a significant decline during aging was evident in bilateral putamen, left temporal, left frontal, and left parietal cortices [214]. It is well documented that there is a close coupling of regional resting CBF with $\mathrm{CMR} \mathrm{O}_{2}$ and cerebral glucose metabolic rate (CMRglc) $[215,216]$. Changes in the ennin ng cular system due to age or disease can significantly alter the BOLD signal. With advancing age, the ennin ng cular system may cause reduced elasticity of vessels, increased atherosclerosis, reduced $\mathrm{CBF}$ in the resting state, and decreased resting $\mathrm{CMRO}_{2}[212,214,217$ 219].

In older adults free from cognitive, neurological, or other disease, fMRI, arterial spin labeling (ASL), PET and SPECT techniques have demonstrated age-related reduction in restingstate CBF [220, 221] and CMRglc [222]. A 5-year follow-up PET study showed that in early MCl, there is decrease in regional rCMRglc without significant change in cognitive function. However, with disease progression, the rCMRglc further declines and becomes more pronounced in clinical stage, which is correlated with continuous decline in cognition [223]. Measurements of fibrillar $A \beta$ burden using Pittsburgh Compound-B (PiB) [224] and fluorodeoxyglucose (FDG) PET measures of CMRglc in cognitively normal late middle-aged to older adult showed that systolic BP was positively correlated with $\mathrm{PiB}$ distribution in frontal, temporal, and posterior ennin ng /precuneus regions. FDG PET results, however, revealed significant inverse correlation between the high BP measures and lower glucose metabolism in frontal and temporal brain regions. This evidence suggests that higher BP (a reflection of possible arterial stiffness), during late midlife may be associated with increased risk of presymptomatic AD [225]. Dementia is said to be closely related to disturbances in CBF (e.g. due to hypertension) [226, 227] and reduction in CMRglc [228]. Severity of these disturbances correlates with the severity of dementia. During ageing/AD, brain capillaries may undergo atrophy/ degeneration, thickened basement membrane, reduced vessel elasticity and amyloid deposition. These may cause cerebral capillary resistance and in conjunction with high blood viscosity may lead to cerebral hypoperfusion and ischemia. Compared with non-demented cases, AD patients possess more capillary angiopathy, extensive capillary A 3 -deposition, and capillary occlusion [229]. Conceivably, the $A D$ pathology is triggered by impaired cerebral perfusion due to microvasculature amyloid angiopathy, which may attenuates glucose and oxygen delivery impacting neuronal function and synaptic pathways. In cortical areas, PIB retention correlated inversely with cerebral glucose metabolism (by FDG PET technique); this relationship was most robust in the parietal cortex [224]. 
The aging-associated cognitive decline (AACD) correlates with significantly reduced glucose metabolism in the right precuneus, posterior ennin ng cortex (PCC), angular gyrus, and bilateral middle temporal cortices; however, such deficits were present in AD patients also [230, 231]. AACD patients who subsequently converted to AD had more extensive glucose hypometabolic changes; in the frontal and temporal cortices, right ennin ng gyrus, right thalamus, and bilateral precuneus [230, 232, 233]. Hippocampus MRglc and frontal cortex PIB uptake were the best discriminators to differentiate normal elderly from $\mathrm{MCl}$, and normal elderly from AD. Thus patterns of regional involvement for FDG and PIB were different [231]. In presymptomatic familial $A D, C M R g l c$ reductions similar to the typical $A D$ pattern occurred in the relative absence of brain atrophy. This observation suggests that PET CMRglc measure may even serve as biomarker in the preclinical diagnosis of AD [234]. Another study similarly showed that hippocampal MRglc reductions (using FDG-PET) during normal aging may predict cognitive decline years in advance of the clinical diagnosis [235]. In fact, a newly emerging rCMRglc reduction is said to correlate with transition from $M C l$ to $A D$ [236]. $A D$ patients show global CMRglc reductions in the brain, but $\mathrm{MCl}$ patients have reduced $\mathrm{CMRglc}$ in the hippocampus and inferior parietal lobe compared to normal elderly. Measurements of CBF and glucose metabolism in patients with $A D$ have shown decreases of $30-50 \%$, compared to age-matched normal controls. FDG-PET imaging has confirmed hypometabolism in the AD brain, revealing glucose metabolic reductions in the parieto-temporal, frontal and posterior ennin ng cortices [237]. In addition, reduction of glucose metabolism in $A D$ occurs also in limbic structures including hippocampus, medial thalamus, mamillary bodies, and PCC [238]. On PIB, AD patients showed significantly increased uptake in the middle frontal gyrus (MFG), PCC, and inferior parietal lobe. A higher [18F]-FDG uptake has been documented in the cortex and the hippocampus of 12month-old APP/PS1 mice (compared with age-matched control mice) in areas close to the amyloid plaques rather than in amyloid-free cerebral tissues. This glucose redistribution may deprive the amyloid-free brain regions, seemingly capable of being viable [239]. Taken together, the above data highlight that memory dysfunction in aging/AD is related to decreased glucose metabolism in several key brain regions.

\subsection{Insulin Resistance}

Insulin modulates cognition and several aspects of normal brain function. $A D$ is associated with brain insulin resistance causing impaired glucose utilization (see below); this is analogous to peripheral insulin resistance and impaired glucose utilization in DM. Insulin signaling in neurons plays a key role in modulating synaptic function and regulating tau phosphorylation and neuronal senescence. Insulin signaling decreases with increasing age and data indicate that insulin signaling is impaired in the AD brain [240]. DM, obesity and hypertension are strongly associated with insulin resistance, conceivably, peripheral 
hyperinsulinemia and insulin resistance may increase the risk of memory impairment and $A D$ [240]. Human data have shown that induced insulin resistance increases both $A \beta$ levels and inflammatory agents in brain. Therefore, their combined effects may upregulate memory impairment and induce AD pathology. Cognitive dysfunction is an under recognized complication of hyperglycemia [240-244]. Chronic hyperglycemia and hyperinsulinemia stimulate the formation of advanced glucose endproducts (AGEs) leading to an overproduction of ROS [245]. Protein glycation and increased oxidative stress are important mechanisms involved in aging, and AD. Notably, there is increased RAGE (receptor for advanced glycation endproducts) expression in aging [246], DM [244], AD [247], and the mouse model of AD [244]. A $\beta$ is eliminated by AGEs and degraded by insulin degrading enzyme (IDE) for which it competes with insulin. Since IDE is much more selective for insulin than for $A \beta$, brain hyperinsulinism may deprive $A \beta$ of its main clearance mechanism [243]. Hyperglycemia and hyperinsulinemia may accelerate brain aging also by inducing tau hyperphosphorylation and amyloid oligomerization [240-244]. AGEs disrupt the neuron function and its bonding to $A \beta$ increases aggregability of Abeta. Glycation of tau protein promotes production of neurofibrillary tangles (NFTs), one of the main pathogenic hallmarks in AD. AGEs in DM causes pathological angiogenesis and apoptosis of neurons. AGE receptor (RAGE) is also the specific $A \beta$ receptor with which it produces ROS; this may promote disruption of mitochondrial function and reduction of neuronal energy [240-244].

Brains from $A D$ patients show substantially downregulated expression of the insulin receptor (IR), and insulin-like growth factor-1 receptor (IGF-1R), and the insulin receptor substrate (IRS) proteins. Similar changes in insulin/IGF-1 signaling (IIS) have been described in DM and animals fed a high fat diet, suggesting that decreased IIS might be involved in the pathogenesis of both DM and AD [241, 242, 248, 249]. The mechanism of neurodegeneration, in part, might be related to (IGF-1 signaling, leading to the proposal that AD is the so-called "braintype diabetes" [250]. Postmortem analyses of AD brains have revealed a markedly downregulated expression of insulin, IGF, IGF-1R, IR, IRS-1 and IRS-2 genes; these alterations keep increasing with progression in neurodegeneration [241, 242, 248, 249]. Hyperglycemia can result in apoptotic cell death in a variety of organs including the brain; however, systemic treatment with IGF-I is reported to inhibits the cellular death [251].

\subsection{Dementia}

$A D$ is the most common cause of dementia. Of the various mechanisms hypothesized for $A D$ pathogenesis, hypoxia/ischemia of the brain occupies a central position since those who are exposed to severe hypoxia-ischemia are more susceptible to developing memory/cognitive dysfunction [252, 253]. The brain is exquisitely sensitive to hypoxia; in AD mice, hypoxia increases $A \beta$ and memory deficits [183]. The direct effect of hypoxia on cerebral endothelial 
expression of several key proteins was evaluated in vitro in the microvasculature of $A D$ mice. Cultured brain endothelial cells were subjected to hypoxia (4-6 h) and expression of HIF-1 $\alpha$, angiopoietin-2 (Ang-2), and matrix metalloproteinase 2 (MMP), and survival/apoptotic proteins (Bcl-xL/caspase 3) quantified [254]. The expression of Ang-2, MMP and caspase 3 was elevated and the anti-apoptotic protein $\mathrm{Bcl}-\mathrm{xL}$ decreased. Results were similar in brain sections from $\mathrm{AD}$ (compared to control mice) [254]. Congruent to the above results of hypoxic effect on rodent endothelial cells, human cerebral endothelial cells similarly displayed induction of caspasemediated cell death by MMP in response to hypoxia-reoxygenation injury [255]. The chronic activation of microglia owing to hypoxia may potentiate neuronal damage through synthesis and release of cytotoxic proinflammatory cytokines, ROS, and proteinases (described above).

Cortical neurons treated in vitro with $A \beta$ concomitantly with hypoxic exposure show increased number of apoptotic neurons relative to treatment with $A \beta$ alone [256]; this further emphasizes the deleterious effect of hypoxia itself that enhances neuronal death $-a$ phenomenon observed in OSA and $A D$ brains. Indeed, impaired oxygen supply has been emphasized to be involved in AD pathogenesis. Decrease in oxygen supply to the brain causes depolymerization of actin filaments in neurons, decreased neuritic sprouting, impaired mitochondrial function, reduced expression of the proteins required to maintain synaptic connections, and ultimately neuronal death [257, 258, 259]. Vascular disease is an important risk factor for $A D$ as delineated above. Therefore, a combined effect of hypoxia, ischemia, and hence hypoperfusion may be causally associated with promoting cognitive impairment/AD [258]. OSArelated hypertension, oxidative stress, and inflammatory milieu, as described above, would cause sustained metabolic stress that may drive progressive dysfunction, apoptosis/necrosis, and eventual brain cell death [260].

Epidemiologically, hypertension precedes onset of dementia by about 30 years [261]. The correlation between hypertension and cognitive dysfunction-dementia has been repeatedly emphasized [164-166, 262- 264]. Neuropathological and imaging studies have shown that hypertensives often contain white matter hyperintensity, demyelination, gliosis, arteriolosclerosis, silent infarcts, and tissue degeneration; all these can lead to cognitive impairment and dementia [264]. Although hypertension itself has been shown to be an independent risk factor for $A D$, it is generally associated with other comorbidities (see below) [265]. One of the premier studies that first provided evidence on the interrelationship between hypertension and cognitive impairment has been the Framingham study [266, 267]. Subsequently, the Rotterdam study, the Kungsholmen study, the Honolulu-Asia Aging Study, and the Epidemiology of Vascular Aging Study supported the results of the Framingham study [264, 268, 269]. Serum amyloid A (SAA) protein has been linked to the development of diabetes, atherosclerosis, stroke, and dementia. SAA correlated positively with $\mathrm{AHI}$, and negatively with 
low oxygen saturation. Plasma SAA levels are $100 \%$ greater in patients with moderate to severe OSA compared with healthy controls, regardless of gender. Elevated SAA in OSA may contribute to an increased risk for cardiovascular and neuronal dysfunction, and hence cognitive decline [270]. Interestingly, an improvement in OSA was associated with a decrease in SAA, independent of the change in BMI [271].

Intermittent apnea/hypoxia induces hypertension (see section 2.2 above). Hypertension during middle adulthood is correlated with a high risk of cognitive decline. The ennin-angiotensin system, implicated in the pathogenesis of hypertension, is also implicated in the pathogenesis of AD [263, 264, 272]. Atherosclerosis, inflammation and the ROS may have a synergistic link with hypertension as interconnected pathophysiological mechanism(s) that promote AD. Additionally, diabetes and hyperinsulinemia may also intertwine with the above mechanisms. Chronic hypertension may impair the blood-brain barrier permeability with deposition of $A \beta$ in brain tissue [273]. In hypertensive mice, microglial activation and IL-1 $\beta$ upregulation were already present in 3-week after hypertension induction, followed by evident $A \beta$ deposition [11]. S100B is a protein biomarker that reflects CNS injury [274]; a linear increase in S100B was evident in mild, moderate, and severe OSA sufferers, reflecting the existence of subtle brain injury in OSA patients $[275,276]$. Several studies mentioned here attest to the hypothesis that in aging, downstream to hypertension, there are many crucial pathologies including hypoperfusion, neuroinflammation, neurovascular alterations, A $\beta$ deposition, NFT formation, synaptic dysfunction/loss, neuritic loss, neuronal dysfunction, and eventual neuronal degeneration/losssuch profound alterations may indeed induce cognitive impairment [10, 269, 273, 277].

The above mentioned pathological alterations - possible harbinger of memory and cognitive decline/dementia, may commence from apnea, hypertension, ennin ng cular perturbations - cerebral hypoperfusion, and glucose hypometabolism, as emphasized above. A recent study has shown differential impact of diabetes and hypertension in terms of adverse effects on grey matter in the rat brain due to diabetes alone or hypertension alone. Only hypertension was associated with vascular luminal reduction and cerebral hypoperfusion on MRI [278]. The root pathological event(s), however, appears to be intermittent apnea/hypoxemia and hypertension due to upregulation of RAS/sympathetic upregulation in sleep disordered breathing. These in conjunction with aging and other existing concomitant stigmata in the aged (such as alcohol consumption, smoking, medication, and concurrent disorders) may exacerbate hypertension, neuroinflammation, microvascular dysfunction, ischemia, impaired glucose metabolism/utilization, reduced ATP synthesis, neuronal dysfunction, and cause cognitive decline. Quite justifiably, therefore, OSA and BP increases are implicated in potentiating pathological process(es) of cognitive decline and dementia/AD [279, 280, 281]. 


\subsection{Final Comments}

A comprehensive literature search was performed on several major areas related to aging and OSA with the main objective to capture any possible link between their pathophysiological mechanisms/pathways and those of AD. The strength of evidence revealed a clear link between OSA-related pathological mechanisms, oxidative stress, immune dysregulation/inflammation, brain hypoperfusion, dysregulation of brain glucose metabolism, and onset of cognitive dysfunction/AD. This review, therefore, recapitulates various studies that have embraced different aspects of the above pathophysiological mechanisms that may result in neuronal dysfunction and the development of cognitive impairment/AD. The current insight juxtaposes the above major physiological abnormalities in a coherent and systematic manner, in order to delineate the trajectory leading to onset of cognitive decline. AD pathology starts years/decades prior to clinical diagnosis. Basically, it is the attenuated neuronal signaling and synaptic failure that underlie initial $A D$ pathology, rather than initial massive neuronal degeneration. The secondary injury mechanism(s) following hypoxia, hypertension, and hypoperfusion are posited to be systemic inflammation inducing ennin ng cular inflammation and microangiopathy, altered clearance of amyloid, and vascular and parenchymal $A \beta$ deposition (see above) (Fig.1). $\quad A \beta$ activates astrocytes and enhances oxidative imbalance, upregulates APP and BACE 1expression - mediated by neuroinflammation [282]. The abnormal production of pro-inflammatory cytokines, chemokines, the complement system, and reactive oxygen and nitrogen species can disrupt nerve terminal's activity causing neuronal dysfunction, loss of synapses, and memory decline. The above vicious phases significantly enhance mitochondrial failure, and amyloidogenic APP processing; A $\beta$ accumulation therefore promotes both oxidative and inflammatory mechanisms - each accelerating the other.

\subsection{Concomitant Adverse Factors Enhance Cognitive Pathology}

A variety of factors, e.g. therapeutic agents or chemical substances may influence/exacerbate cognitive perturbations in the elderly. Of course the most important risk factor for sporadic AD is aging. Cognitive impairment without dementia is present in about $16 \%$ to $33 \%$ of adults over 65 years [283]. Of 554 well-functioning members of an elderly (70+) cohort, $19.3 \%$ were amnestic $\mathrm{MCl}, 15.5 \%$ met non- amnesic $\mathrm{MCl}$ criteria, $43.5 \%$ had impairment on at least one neuropsychological test, and the rate of depression was about $7.0 \%$ [284]. A relationship between cognitive complaints/impairment and depressive symptoms has been documented in older individuals [285]. Literature survey of 55 papers, between 1995 and 2006, on the Prevalence of depression in OSA gave a figure that ranged between 7 and 63\% [286]. A vicious cycle exists in that heavy drinking contributes to depressive symptoms, and alcohol is consumed to cope with depressive mood [287]. Age-associated brain proinflammatory cytokine 
system has been implicated to play a pathophysiological role in the increased prevalence of depression generally found in the elderly [288]. Aging exacerbates depressive-like behavior in mice also in response to activation of the peripheral innate immune system. The data showed that depression and its deleterious effect on the brain enhances neuroinflammatory burden and degenerative progression [289]. There is evidence that depression is associated with peripheral cell-mediated activation, inflammation, and induction of oxidative and nitrosative stress pathways, as well as central microglial activation, a decrease in CBF, and increased apoptosis [289]. The above pathology may also occurs in OSA and $A D$, and the common denominator appears to be oxidative and nitrosative stress pathways. Consequently, progressive $A \beta$ production and vascular pathology both contribute to and are affected by oxidative stress [184].

Age-dependent cerebral atrophy and cognitive dysfunction occurs in senescence. Cerebral atrophy is common in normal elderly [290] and mice [291]. Many substances having deleterious effects in the elderly may include sodium chloride, substances of abuse, sympathomimetics, nonsteroidal anti-inflammatory drugs (NSAIDS), sex steroids, immunosuppressives, ennin ng cula, antidepressants, antipsychotics, ergot alkaloids, and anesthetic agents, to name a few [292]. Glucocorticoids are among the most widely prescribed medications and despite their beneficial effects (immunosuppression and anti-inflammation) they have the potential for causing hypertension. Of note, environmental toxicants such as pesticides, chemicals, and heavy metals can also damage cells by converging on adverse pathways enhancing oxidative stress, depleting glutathione and downregulating cellular signaling, and enhancing neurodegeneration in the elderly [293].

Frequent moderate alcohol consumption is quite common in older adults, and $12.3 \%$ of male and $8.4 \%$ of female were found to be heavy/binge drinkers. The frequency of alcohol intake is significantly correlated with the onset of depression, even at a younger age [294]. An association exists between alcohol consumption ( $>2$ drinks) and several deleterious effects, including hypertension [295, 296]. There is evidence of an association between higher alcohol consumption and brain atrophy; however, in women, alcohol has detrimental effects on the brain even at lower levels of consumption. Alcoholics have significantly decreased corpus callosum ( $48 \%$ ), reflecting cortical damage; the degree of brain atrophy correlates with the quantity of ethanol intake [297]. Volumetric MRI analyses have shown atrophy of corpus callosum in AD patients also with an annual atrophy rate of total corpus callosum, splenium, and rostrum being $7.7 \%,-12.1 \%$, and $-7.3 \%$, respectively [298]. Rate of atrophy of the corpus callosum splenium, which was the largest, was correlated with progression of dementia severity [299]. Chronic alcohol consumption in well-nourished persons shows a high degree of brain shrinkage with age, and significant impairment of brain function for neuropsychological and cognitive tests [300]. In 
addition, ethanol consumption (dose-dependently) produces widespread decreases in functional activity, reflected by lower rates of glucose utilization in disparate brain regions subserving sensory, motor, and limbic systems [301]. Furthermore, global CBF was lower in heavy alcohol consumption (analyses controlled for age, gender, and carotid intima-media thickness) [302]. A recent study (using 99mTc-ECD SPECT) in alcoholics found that the rCBF was significantly lower bilaterally in frontal, parietal, and temporal lobes, and in basal ganglia [303]. It is well established that cigarette smoking (CS) is yet another independent risk factor for cardiovascular disease. Mice exposed to 32 wk of cigarette smoke had markedly higher BP, higher afterload, higher ROS generation, and significantly faster blood NO decay [304].

\subsection{Hypoxia, hypertension, and Hypoperfusion: Neurocognitive Impairment}

The hypoxia signal transduction pathway is implicated in playing a cardinal role in cerebrovascular ischemia, and neurodegeneration [305]. Neurons in the hippocampus and other neocortical foci were shown to be selectively affected by cerebral ischemia [306, 307]. The quintessential neuropathological lesions of $A D$ are neurofibrillary tangles (NT) and amyloid plaques; these are mainly composed of abnormally phosphorylated tau and $A \beta$, respectively. $A \beta$ accumulation in the $A D$ brain is considered to promote synaptic dysfunction, neurodegeneration and neurocognitive dysfunction. In as much as declining neurocognition in older individuals may be correlated with $A \beta$-induced pathology, the latter is a downstream process linked to cognitive decline/AD. As patients progress to dementia, clinical decline and neurodegeneration advance, independently of amyloid accumulation. The presence of brain $A \beta$ alone is not sufficient to produce cognitive decline, since the elderly who do not progress to $A D$ may also possess substantial cerebral $A \beta$; rather, memory impairment and the rate of cognitive dysfunction are driven by the rate of neurodegeneration [308]. Hypoperfusion of brain is an important risk factor for $A D$ [310]. Cerebral ischemia has a direct effect in up-regulating expression of the APP and in attenuating $A \beta$ clearance from the brain $[309,310]$. Vascular ischemic/inflammatory/A $\beta$ pathology, therefore, lowers the threshold for promoting AD-related pathology. Amyloid imaging studies have shown that amyloid deposition is an early event long before dementia, beginning insidiously in cognitively normal individuals; subtle cognitive decline, and functional and structural brain changes suggestive of incipient $A D$ occur subclinically. Autopsied brains of most individuals over 65 and without clinical dementia contain senile amyloid plaques (SP) and NFTs in several brain regions in general and the hippocampus and entorhinal cortex in particular. As patients progress to dementia, clinical decline and neurodegeneration accelerate in the wake of amyloid accumulation [308]. This underscores that although formation of SPs and NFTs may indeed be intrinsic to the normal aging process, SPs and NFTs are more numerous and widespread when the elderly have significant cerebrovascular disturbance, such as hypertension, hypoperfusion, and hypoglycemia - that enhance neurodegeneration. 
In paucity of oxygen and in aging, HIF-1 binds to its promoters/enhancers, and activates several genes including the one involved in cell death. Activation of the HIF-1 pathway, via disparate risk factors such as age, hypoxia, hypertension, hypoperfusion, and neuroinflammation, may facilitate $A \beta$ deposition and contribute to $A D$ pathogenesis. There is a functional hypoxiaresponsive element in the BACE1 gene promoter. Hypoxia increases BACE1 gene transcription both in vitro and in vivo, up-regulates beta-secretase cleavage of APP, and enhances A production [311]. Indeed, in Swedish mutant APP transgenic mice, hypoxia significantly increased $A \beta$ deposition and neuritic plaque formation and potentiated memory deficit. This clearly documents that hypoxia can promote $A D$ pathology, through a molecular mechanism linking vascular factors such as hypoxemia and hypoperfusion to $A D$ [311]. Finally, although $A \beta$ deposition and hippocampal atrophy (and those of other brain regions), may occur in elderly/AD subjects, the primary events in this pathologic cascade are OSA-related metabolic dysfunctions.

Apoptosis has been documented in the CNS in ageing [312] and in ennin ng cular diseases [313]; it involves the activation of caspases, which cleave DNA molecules into small fragments and disintegrate the neuronal cell. Chronic intermittent hypoxia $(\mathrm{CIH})$, the integral and essential component of OSA is associated with substantial cortico-hippocampal and brainstem damage leading to impairments of neurocognitive, respiratory and cardiovascular functions (see above). Although the precise molecular events leading to $\mathrm{ClH}$-mediated neuronal cell death remain elusive, the oscillation of $\mathrm{O}_{2}$ concentrations during $\mathrm{ClH}$ is linked to hypoxia-re-oxygenation and ischemia-reperfusion, and could therefore increase cellular production of ROS. Neurons may undergo apoptosis in response to the above mentioned injurious processes, and indeed necrosis occurs in the adult medulla oblongata when subjected to hypoxia-ischemia [120, 314-317].

\subsection{Reconciling with Theories of AD Pathogenesis}

The current paradigm on etiopathogenesis of cognitive impairment/dementia in $A D$ is reconcilable with existing theories on $A D$ pathogenesis. A widely discussed theory posits that $A \beta$ deposition is causally linked to AD. As alluded to above, there is an absence of correlations between amyloid deposits and dysfunctional cognition. The presence of amyloid loads in normal subjects is similar to $A D$, and animal models with behavioral abnormalities are independent of amyloid deposition, plus a lack of amelioration in $A D$ with therapies to reduce amyloid load clearly reflect its lack of causal link (also see above). However, extensive research to date has failed to substantiate with convincing evidence that brain amyloid is indeed the main initial cause of neurodegeneration in aging/AD. 
Accumulating evidence shows that obesity causes a chronic low-grade systemic inflammation during mid- and late-life, and increases the risk for neurodegenerative diseases, and dementia including AD [318-321]. Obesity leads to an abnormal activation of neuroendocrine and pro-inflammatory pathways [322]. Activated white adipose tissue increases the synthesis of proinflammatory cytokines, such as IL-6, IL-1, IL-8, TNF- $\alpha$, IL-18, while anti-inflammatory regulatory cytokines, such as IL-10 are decreased [323]. Not surprisingly, higher BMI was shown to be associated with GMV decrease (in the left orbitofrontal, right inferior frontal, and right precentral gyri, a right posterior region including the parahippocampal, fusiform, and lingual gyri, and right cerebellar regions) [318, 324, 325]. Several studies highlight that obesity and metabolic disorders are linked to $A \beta$ accumulation in $A D[326,327]$. High fat diet has been shown to increase $A \beta-40$ and A $A-42$ burden in the cortex of Tg2576 mice [328] and 3xTg-AD mice [329]. However, the observed $A \beta$ changes were not associated with alterations in total APP, C-terminal fragments ( $\alpha$ and $\beta$ cleavage products) of APP or soluble oligomers. This suggests that high-fat diet promotes $A \beta$ generation through pathways that may not utilize the APP. It should be pointed out then, that aging, OSA/hypoxia, and obesity may share some common mechanisms such as inflammation oxidative stress, and microgliosis [330-333].

Evidence supports that progressive impairment in brain's glucose metabolism and response to insulin and IGF causes deficits in energy metabolism in AD. The latter may lead to increased oxidative stress. Recent clinicopathological studies have shown no evidence that amyloid plaques increase in the brains of diabetic patients [334]. Hence, Diabetes, may not be directly related to a higher risk of amnestic $\mathrm{MCl}$ and neurodegeneration. The above mentioned does not conflict with the current paradigm. Recurrent intermittent hypoxia and sleep fragmentation impair glucose metabolism; these perturbations cause a stress response which increases sympathetic activity, altered leptin levels resulting in weight gain, proinflammatory cytokines, cerebral microvascular disease, and $A \beta$ generation (see above). Chronic hyperglycemia is implicated in promoting the development of cerebral microvascular disease. Other possible factors triggering cognitive dysfunction in OSA and DM may include dysregulation of the hypothalamic-pituitary-adrenal axis [335]. Indeed increased cortisol concentration is linked with cognitive impairment.

A common observation in both $D M$ and $A D$ is the desensitization of insulin receptors in the brain. Insulin acts as a growth factor in the brain and is neuroprotective; it activates dendritic sprouting, regeneration and stem cell proliferation [336]. However, insulin resistance and hyperinsulinemia does not induce plaque formation in brain or AD-like abnormalities in mice [337]. Importantly, AD-type neurodegeneration can be produced experimentally by selectively impairing insulin/IGF functions "only in conjunction with oxidative stress" [250]. There is copious 
evidence of insulin resistance in OSA [338-343]. These observations support the current paradigm in that one of its major tenets viz. oxidative stress is of pivotal importance. It has been suggested that decreased insulin/IGF-1 signaling might be involved in the pathogenesis of both $D M$ and $A D$. DM may cause brain atrophy but lack many features that typify $A D$; thus $D M$ may contribute to, but is not sufficient to cause $A D$ [344]. However, DM patients suffering from $A D$ accumulate less $A \beta$ compared to non-diabetic $A D$ patients, raising the question whether the changes in insulin/IGF-1 signaling reflect compensatory counter-regulation to neurodegeneration. It is claimed in a recent study that the intracerebroventricular administration of subdiabetogenic doses of streptozotocin (STZ) in rats (not mice) can induces an insulin-resistant brain state, and is said to produce brain pathology and behavioral changes resembling those of AD [345].

\section{$\underline{7.4 \text { Mitochondrial Dysfunction - OSA and AD }}$}

Mitochondria oxidize glucose to generate the energy rich adenosine triphosphate, in most mammalian cells including neurons. Mitochondrial dysfunction however has been implicated in a number of diseases including dementia [346-348]. ROS may be produced by mitochondria, owing to hypoxia-ischemia-hypertension-inflammation mediated oxidative stress. Apart from energy production, mitochondria are the main intracellular source of ROS; they are also intimately involved in calcium homeostasis, synaptic plasticity, neurotransmitter release, and apoptosis [349, 350]. Thus, mitochondrial dysfunction is escalated in aging [351], OSA [187, 352], and AD $[346,353-356]$ causing profound dysfunction of the brain - a high-energy organ. Oxidative stress and mitochondial dysfunction may be pivotal contributors to neurocognitive dysfunction and neuronal apoptosis/failure in the evolution of $\operatorname{AD}[346,353,357,358]$. The restriction of oxygen and blood flow, i.e. apnea/hypoxia and ischemia, and then inflammation promote ROS generation; downstream both $A \beta$ plaques and NFTS are reported to be sites for redox cycling and generation of ROS [353, 359]. Notably, following cerebral ischemia, as in OSA and AD, the activation of NADPH oxidase (its subunit, NOX2), increased oxidative stress, and DNA damage may be associated with neuronal death. Ischemic injury facilitates the latter via accumulation of poly(ADP-ribose) polymers, the translocation of apoptosis-inducing factor (AIF), and cytochrome c release from mitochondria $[360,361]$. Mitochondrial abnormalities in AD are associated with changes in mitochondrial dynamics due to $A \beta$ accumulation within this organelle, acting as a direct toxin. Moreover, mitochondrial function is attenuated by $A \beta$ that induces activation of glutamate $\mathrm{N}$-methyl-D-aspartate receptors (NMDARs), excessive release of calcium from endoplasmic reticulum (ER) that enhance mitochondrial calcium dyshomeostasis thereby ultimately damaging neurons [362].

\subsection{Hypoxia, Hypertension and Hippocampus - Cognitive Impairment}


Untreated OSA persists over decades in sufferers, and hence is eminently capable of causing significant neuronal damage and apoptosis [363], and neurocognitive deficits [364]. $\mathrm{ClH}$ increases cytoarchitectural disorganization and apoptosis in brain areas involved in learning and memory, such as the hippocampal CA1 region and the fronto-parietal cortex in a rat model of OSA [365, 366]. These changes correlated with decreased membrane excitability, synaptic plasticity of CA1 neurons, and memory deficits [367]. It is well known that the hippocampal circuit is critical for the formation of spatial memory. However, a significant decrease of long term potentiation (LTP) occurs in the hippocampus of $\mathrm{ClH}$-treated mice, providing an explanation in part, for the memory deficits associated with OSA in humans and animal models [368]. A number of factors have been proposed to delineate the mechanism of $\mathrm{ClH}$-induced memory deficits; these include decreased CREB phosphorylation [367], oxidative stress [115, 369], NO [370], and inflammation [371]. Their respective deleterious effects, "as concerted hits", may promote apoptosis $[363,366]$ and enhance hippocampal dysfunction leading to memory/cognitive impairment.

In healthy elderly without dementia, elevated neocortical PIB retention has been shown in the hippocampus; such correlation emphasizes upregulation of hippocampal synaptic degradation, neuronal degeneration, and GMV loss [372]. Hippocampus is a highly plastic brain structure that is damaged by a host of stimuli in persons having hypoxia, hypertension, hypoperfusion, hypoglycemia, diverse stresses and central corticosteroid-inducing mechanisms. Hypoxia and hypertension can be potentially noxious in damaging hippocampus through subnormal oxygen delivery, and rCBF attenuation [373], and promoting cognitive decline/AD [374-377]. Hippocampal vulnerability to ischemia has been documented in the elderly who had midlife untreated BP; they showed late-life hippocampal atrophy [374]. In the Australian OPTIMA longitudinal study, both High and low blood pressure levels were found associated with faster cognitive decline in AD patients [377]. Non-impaired older hypertensive subjects (with moderate hypertension) possess smaller whole brain volume and an increased burden of subcortical and periventricular white matter lesions [375]. Cognitively normal subjects with hypertension showed decreased rCBF in the left hippocampus [373]. In addition, decreased rCBF was observed bilaterally in the putamen, globus pallidus, anterior ennin ng gyrus (with extension to the subcallosal region), and in left posterior ennin ng gyrus medial precuneus, inferior and superior frontal, inferior parietal, left orbitofrontal, and superior temporal cortices [373].

The hippocampus is one of the most severely affected areas in AD. Stress plus inflammation have a dramatic effect in activating microglia and astroglia in the hippocampus causing a loss of about $50 \%$ of CA1 pyramidal neurons [378, 379]. The NTS projects to the hippocampus [380] and hippocampus constantly receives visceral ascending information from the NTS. The NTS $\rightarrow$ hippocampus pathway encompasses relay sites including locus coeruleus, 
dorsal raphe nucleus, paraventricular thalamic nucleus, nucleus reuniens, hypothalamus, and nucleus of the diagonal band and medial septum [380, 381]. The parabrachial nucleus (PBN) also provides the key linkage, i.e. from the NTS $\rightarrow$ parabrachial nucleus (PBN) $\rightarrow$ hippocampus. The NTS projects to the basal forebrain (medial septum/diagonal band), the locus coeruleus, and the bed nucleus of the stria terminalis [382]. In AD, both adrenergic and cholinergic supply is dysfunctional. This may be due to dysfunctional noradrenergic locus coeruleus and medial septum/diagonal band cholinergic - both provide inputs to the hippocampus [383, 384], and both are linked to the NTS, which may be dysfunctional and inflamed (discussed above in the NTS section). The dysfunctional NTS, therefore, may conceivably impact hippocampal functions directly and indirectly, thus compromising memory and cognition [3, 4, 6, 17-19, 110]. The NTS projects efferents to a large number of cortical and sub-cortical regions, including the PFC and ennin n. Thus, its inflammation (in chronic systemic and neuro- inflammation) may cause dysfunctional synaptic transmission and attenuate multitude of efferent signaling pathways. Owing to several risk factors discussed above, a dysfunctional and inflamed NTS (see discussion above) would have an adverse global neurodegenerative impact.

\subsection{Final Remarks}

\subsection{OSA, Obesity, Diabetes and Hypertension}

In obese sleep apneics, visceral fat e.g. when significantly greater than obese controls, is strongly associated with insulin resistance and inflammation [385-387]. Obesity plays a major role in the pathogenesis of sleep apnea; Cytokines and insulin resistance are mediators of excessive daytime sleepiness (EDS) and sleep apnea in humans. In obese persons hypothalamic $\mathrm{CRH}$ neuron is hypoactive providing additional evidence on the potential role of central neural mechanisms in mediating depressed ventilation and development of OSA [385, 386]. Thus, obesity via inflammation, insulin resistance, visceral adiposity, and hypofunctioning central neural mechanisms (e.g. hypothalamic $\mathrm{CRH}$ ), may synergize in the pathogenesis of sleep apnea, and its associated cardiovascular and metabolic co-morbidities [386]. The pathogenic role of insulin resistance in OSA can be appreciated from women with the polycystic ovary syndrome (PCOS) (a condition associated with hyperandrogenism and insulin resistance); compared to controls, PCOS women are much more likely to possess SDB and daytime sleepiness. Furthermore, interestingly the risk for OSA among nonobese women with PCOS is very low, but the risk for OSA in obese PCOS is high [388]. Recently, two "subtypes" of PCOS have been documented - i.e. PCOS with OSA and PCOS without OSA. PCOS women with OSA

may be at much higher risk for diabetes and cardiovascular disease than PCOS women without OSA, reflecting that these two subtypes may possess distinct metabolic and endocrine attributes [389]. This aspect was further delineated in that glucose intolerance and insulin resistance were 
correlated with the presence and severity of OSA [390] (Lin et al., 2012). Among PCOS women with normal glucose tolerance, the presence of OSA was associated with a nearly 2-fold higher fasting insulin level. The severity of OSA was highly significant in predicting the fasting concentrations of glucose and insulin [391]. Conversely, only the most insulin-resistant subset of obese individuals was found to be at highest risk for OSA [392] (Liu et al., 2012). In the current paradigm, OSA (hypoxia/hypoxemia) has a central role. This risk factor is the common denominator in the pathological cascade that promotes the onset of inflammation, oxidative stress, cardiovascular and metabolic dysfunctions (see above).

$D M$ is associated with peripheral insulin resistance, whereas $A D$ is associated with brain insulin resistance and insulin deficiency. In a C57BL/6 mouse model of obesity and DM, high fat diet (HFD) feeding (for 16 weeks) doubled body weight and caused DM [393]. HFD also caused brain insulin resistance evidenced by reduced insulin receptor binding and reduced brain weight. However, HFD-fed mouse brains lacked the typical $A D$ pathology, i.e. an increases in $A \beta$ or ennin n-tau, or IGF signaling impairments or acetylcholine dyshomeostasis. This study underscores that obesity and DM may cause brain atrophy with insulin resistance, oxidative stress, and cytoskeleton degradation, but fails to promote many crucial features of $A D$ neuropathology. This clearly indicates that obesity or DM alone is not sufficient to cause $A D$ [393]. In a study that evaluated the prognostic predictors in AD, patients with $\mathrm{DM}$ had a $65 \%$ reduced risk of fast cognitive decline, compared to AD patients without DM [394].

Renin-angiotensin system (RAS) contributes to cognitive decline and brain damage via chronic cerebral ischemia. Chronic cerebral hypoperfusion in C57BL/6J mice significantly increased brain ennin activity and angiotensinogen expression; this was attributed to activated astrocytes and microvessels [395]. Utilizing human ennin (hRN) and human angiotensinogen (hANG) gene chimeric transgenic ( $\mathrm{Tg}$ ) mice, it was documented that cerebral surface blood flow was greatly reduced in hRN/hANG-Tg mice (20-week-old). Superoxide anion production occurred in the brain of these 10-week-old mice; it further increased with an increase in NADPH oxidase activity . Moreover, the brain of hRN/hANG-Tg mice also had increased expression of p47(phox) and Nox4 [396], enhanced ischemic brain damage, due mainly to marked reduction of cerebral blood flow and enhanced oxidative stress [397]. In keep with epidemiological evidence that hypertension may accelerate the onset and progression of $A D$, experimental hypertension induced in Tg2576 mice was associated with significantly enhanced accumulation of $A \beta$ peptides in brain. These results indicate that hypertension may promote AD-type neuropathology in Tg2576 mice [398]. Additionally, OSA (hypoxia/hypoxemia) which promotes hypertension also induces $A \beta$ neuropathology in brain. Accumulating evidence showed that transient hypoxia can cause an increase in the gene expression of $\beta$-secretase $[399,400]$. $A \beta$ deposition that begins 
insidiously is an early event in the cascade leading to cognitive impairment - but it has prerequisites, as referred to above. Several factors may independently contribute to $A \beta$ accumulation and neurodegeneration. However, significant and accelerated cognitive decline and functional and structural brain changes suggestive of incipient $A D$ may occur when several stigmata including OSA, inflammation, oxidative stress, and environmental factors may enhance each other and converge in upregulating $A \beta$ production in an obese aged person.

\subsection{Critique of the Current Paradigm}

Multifactorial injuries including hypoxia, ischemia, and hypometabolism are inherent in the current paradigm of $A D$ pathogenesis. An understanding of the latter may require a novel approaches to neuronal injury. A range of 'injury trajectories' suggest a range of injuries and their magnitudes - progressing to a crucial tipping point between neuronal viability or its death. This may involve a mutual antagonism between "injury-driven damages" and "salvageable stress responses" - representing impending death or recovery, respectively. Hence, it is unlikely that decreasing amyloid plaques alone could divert a pathological system from a pro-death trajectory to a pro-survival trajectory, since there are a number of known concomitant pathologies in progress. Two examples: depression is common in $A D$, selective serotonin reuptake inhibitor sertraline (antidepressants - used commonly in treatment) did not demonstrate efficacy for the treatment of symptoms of depression in AD patients [401]. Second, hundreds of agents have shown neuroprotection in preclinical animal studies for brain ischemia; however, these carefully chosen agents (over 100) have failed in clinical trials of stroke neuroprotection [402]. Not unexpectedly, therefore, the therapeutic attempts to ameliorate $A D$ a multifactorial therapeutic approach. What should be the approach to promote neuronal survival in a scenario of progressive neuronal cell injury in AD?

The answer to the above question is that an alternative way may be required to think about brain injury in AD. Lets start with the concept that existing data may be interpretable to suggest that the pathological stigmata in $A D$ induce several nonlinear, extracellular and intracellular pathways that influence (i) pro-survival and (ii) pro-death changes, the mutual antagonism of which may cause outcome [403]. The currently dominant paradigms extant in the $A D$ field are 'several pathological cascades'. In the current paradigm, however, they include hypoxia/hypoxemia, hypertension, obesity, and DM. The term 'cascade' basically suggests a linear sequence of events - of cause and effect. But accumulated research data have revealed

so many heterogeneous changes in neuronal physiology and metabolism; thus so many heterogeneous cascades - make it difficult to conceptualize how these myriad pathological alterations occur in a single sequential manner, as depicted in Fig. 1. Thus, this makes the notion that neuropathogenesis of $A D$ is a function of a single molecular cascade (regardless of which 
one) increasingly threadbare. The next logical step therefore requires the implementation of the concept that "total damage and total stress responses" (alluded to above) change in time as a function of cumulative injury-repair magnitude [403]. This necessarily envisages a relationship between "total damage/injury and total induced stress responses", resulting in a tipping point; in the case of $A D$ - ongoing neurodegeneration. This above consideration expands the scope of inquiries to encompass multiple intertwining pathways in a diverse complex pathobiological system, such as the multifactorial neuropathology of $A D[404,405]$. If one stacks individual damage mechanism (with their respective damage mechanism's intensity), this would gives the total amount of damage experienced by the system. The outcome is a function of the aggregate effect of all injury-induced damage. The seminal concept is - there is a threshold amount of damage below which the neuron survives, and above which it dies.

It follows therefore, that in complex relationships, one may question the validity of serial relationships. Here one needs to be cognizant of the existence of interlocking networks and pathways, each with the ability to buffer changes, and each with the ability to upregulate the other, depending on the metabolic/neuropathologic milieu in a given point in time. This must be quite likely in the current paradigm also. Hence, in so-called serial bivariate relationships, such as OSA inducing hypertension, hypertension inducing inflammation, and inflammation inducing neurodegeneration - they all are known to induce oxidative stress and $A \beta$ generation, and they all participate in eventual neurodegeneration, via enhancing the levels of each other owing to the well known elasticity and confluence of metabolic/physiological networks. A host of factors, delineated here, therefore, possibly promote cascades that are both linear and inter-connecting, and thus potentiate disease progression, chronicity, and cognitive impairment/dementia.

\section{$\underline{9.0 \text { Conclusions }}$}

The bigger question is - how aging with no cognitive impairment progresses to dementia in some elderly? AD therefore presents a challenge in respect of unraveling the fundamental pathophysiological mechanism(s). The thesis of this article highlights a wide range of factors possibly involved in promoting this disease. Logically, the multiple effects of hypoxia, hypoxemia, hypertension, and cerebral ischemia have the potential to explain the expression of several key pathologies such as inflammation, microvascular dysfunction and deposition of the amyloid beta protein; these appear to be both a cause and consequence of disease progression. While the very basic pathogenetic mechanisms responsible for $A D$ remain unelucidated - a reasonable place to start will be hypoxia, dysfunctional ponto-medullary nuclei, sympathetic activation, neuroinflammation, cerebral hypoperfusion and depressed glucose metabolism; these may contribute to dyshomeostasis, neuronal dysregulation/apoptosis, and promote cognitive dysfunction/dementia. Fundamentally, OSA is associated with hypoxia, hypoxemia and 
hypertension. Elevated BP is an important risk factor leading to cerebral ischemic changes. Compared to other tissues, brain has higher oxygen and glucose consumption; however, its high lipid content may also generate more ROS. Common OSA-associated cardiovascular disorders including coronary artery disease, heart failure, and cardiac arrhythmias are well documented to promote brain microangiopathy and infarcts. Evidence indicates that intermittent hypoxia/hypoxemia alone may cause elevated BP, increased hematocrit, hyperglycemia, elevated ROS, vasoconstriction, hypoperfusion, and brain glucose hypometabolism. Consequently, in conjunction with the above mentioned stigmata, data on entities such as neuroinflammation, coagulopathy, endothelial dysfunction, and ischemia-reperfusion implicate them to promote amyloid oligomerization and tau hyperphosphorylation. In susceptible elderly, an ongoing switch in the balance between the above mentioned pathologies and normal homeostasis may upregulate cascades of $A \beta$ production and NFTs, leading to progressive cognitive decline and eventual dementia. A matrix of factors discussed here to delineate possible pathogenesis of $A D$ raises the inevitable deduction that $A D$ is not a single entity, and should be considered as a syndrome.

\subsection{References}

[1] Seubert P, Oltersdorf T, Lee MG, Barbour R, Blomquist C, Davis DL, Bryant K, Fritz LC, Galasko D, Thai $\mathrm{LJ}$ (1993) Secretion of $\beta$-amyloid precursor protein cleaved at the amino terminus of the $\beta$-amyloid peptide. Nature 361: 260-263.

[2] Selkoe DJ (2011) Resolving controversies on the path to Alzheimer's therapeutics. Nature Medicine 17: 1060-1065.

[3] Daulatzai MA (2009) The pharyngeal landscape: its length and breadth. J Sleep Res 18: 483-484.

[4] Daulatzai MA (2011) Role of Sensory Stimulation in Amelioration of Obstructive Sleep Apnea. Sleep Disorders 2011 (2011), Article ID 596879, 12 pages, doi:10.1155/2011/596879.

[5] Young T, Palta M, Dempsey J, Skatrud J, Weber S, Badr S (1993) The occurrence of sleep-disordered breathing among middle-aged adults. N Engl J Med 328: 1230-1235.

[6] Daulatzai MA (2010a) Early stages of pathogenesis in memory impairment during normal senescence and Alzheimer's disease. J Alzheimers Dis 20: 355-367.

[7] Ayappa I, Rapaport BS, Norman RG, Rapoport DM (2005) Immediate consequences of respiratory events in sleep disordered breathing. Sleep Med 6: 123-130.

[8] Ronksley PE, Hemmelgarn BR, Heitman SJ, Hanly PJ, Faris PD, Quan H, Tsai WH (2009) Obstructive sleep apnoea is associated with diabetes in sleepy subjects. Thorax 64: 834-839.

[9] Butt M, Dwivedi G, Khair O, Lip GY (2010) Obstructive sleep apnea and cardiovascular disease. Int J Cardiol 139: 7-16.

[10] Bosc LV, Resta T, Walker B, Kanagy NL (2010) Mechanisms of intermittent hypoxia induced hypertension. J Cell Mol Med 14: 3-17. 
[11] Carnevale D, Mascio G, Ajmone-Cat MA, D’Andrea I, Cifelli G, Madonna M, Cocozza G, Frati A, Carullo P, Carnevale L, Alleva E, Branchi I, Lembo G, Minghetti L (2012) Role of neuroinflammation in hypertensioninduced brain amyloid pathology. Neurobiol Aging 33, 205.e19-29.

[12] Janssens JP, Pautex S, Hilleret H, Michel JP (2000) Sleep disordered breathing in the elderly. Aging (Milano) 124: 17-29.

[13] Bombois S, Derambure P, Pasquier F, Monaca C (2010) Sleep disorders in aging and dementia. J Nutr Health Aging 14: 212-217.

[14] Drager LF, Bortolotto LA, Lorenzi MC, Figueiredo AC, Krieger EM, Lorenzi-Filho G (2005) Early signs of atherosclerosis in obstructive sleep apnea. Am J Respir Crit Care Med 172: 613-618.

[15] Pallayova M, Steele KE, Magnuson TH, Schweitzer MA, Hill NR, Bevans-Fonti S, Schwartz AR (2010) Sleep apnea predicts distinct alterations in glucose homeostasis and biomarkers in obese adults with normal and impaired glucose metabolism. Cardiovasc Diabetol 9: 83.

[16] Dempsey JA, Veasey SC, Morgan BJ, and O'Donnell CP (2010) Pathophysiology of Sleep Apnea. Physiol Rev 90: 47-112,

[17] Daulatzai MA (2012a) Dysfunctional nucleus tractus solitarius: its crucial role in promoting neuropathogentic cascade of Alzheimer's dementia-a novel hypothesis. Neurochem Res 37: 846-868.

[18] Daulatzai, MA (2012b) Memory and cognitive dysfunctions in Alzheimer's disease are inextricably intertwined with neuroinflammation due to aging, obesity, obstructive sleep apnea, and other upstream risk factors. In Memory Impairment: Causes, Management and Risk Factors, Horizons in Neuroscience Research. Volume 8, Eds. Costa A, Eugenio Villalba E, Eds. Nova Science Publishers, Hauppauge, NY, USA. In Press.

[19] Daulatzai, MA (2012c) Pathogenesis of cognitive dysfunction in patients with Obstructive Sleep Apnea: A Hypothesis with Emphasis on the Nucleus Tractus Solitarius. Sleep Disorders 2012, Article ID 251096, 18 pages, doi:10.1155/2012/251096

[20] Row BW (2007) Intermittent hypoxia and cognitive function: implications from chronic animal models. Adv Exp Med Biol 618: 51-67.

[21] Skoog I, Lithell H, Hansson L, Elmfeldt D, Hofman A, Olofsson B, Trenkwalder P, Zanchetti A; SCOPE Study Group (2005) Effect of baseline cognitive function and antihypertensive treatment on cognitive and cardiovascular outcomes: Study on Cognition and Prognosis in the Elderly (SCOPE). Am J Hypertens 18: 1052-1059.

[22] Foster GE, Brugniaux JV, Pialoux V, Duggan CT, Hanly PJ, Ahmed SB, Poulin MJ (2009) Cardiovascular and ennin ng cular responses to acute hypoxia following exposure to intermittent hypoxia in healthy humans. J Physiol 587: 3287-3299.

[23] Chen TI, Lai CJ, Hsieh CJ, Tsai KL, Yang KT (2011) Differences in left ventricular cardiomyocyte loss induced by chronic intermittent hypoxia between spontaneously hypertensive and Wistar-Kyoto rats. Sleep Breath 15: 845-854.

[24] Levy P, Tamisier R, Arnaud C, Monneret D, Baguet JP, Stanke-Labesque F, Dematteis M, GodinRibuot D, Ribuot C, Pepin JL (2012) Sleep deprivation, sleep apnea and cardiovascular diseases. Front Biosci 4: 2007-2021.

[25] Peppard PE, Young T, Palta M, Skatrud J (2000) Prospective study of the association between sleepdisordered breathing and hypertension. N Engl J Med 342: 1378-1384.

[26] Shahar E, Whitney CW, Redline S, Lee ET, Newman AB, Javier NF, O'Connor GT, Boland LL, Schwartz JE, Samet JM (2001) Sleep-disordered breathing and cardiovascular disease: cross-sectional results of the Sleep Heart Health Study. Am J Respir Crit Care Med 163: 19-25. 
[27] McArdle N, Hillman D, Beilin L, Watts G (2007) Metabolic risk factors for vascular disease in obstructive sleep apnea: a matched controlled study. Am J Respir Crit Care Med 175: 190-195.

[28] Shiina K, Tomiyama H, Takata Y, Yoshida M, Kato K, Saruhara H, Hashimura Y, Matsumoto C, Asano $\mathrm{K}$, Usui Y, Yamashina A (2010) Effects of CPAP therapy on the sympathovagal balance and arterial stiffness in obstructive sleep apnea. Respir Med 104: 911-916.

[29] Ziegler, M. G., Mills, P. J., Loredo, J. S., Ancoli-Israel, S. \& Dimsdale, J. E (2001) Effect of continuus positive airway pressure and placebo treatment on sympathetic nervous activity in patients with obstructive sleep apnea. Chest 120: 887-893.

[30] Kohler, M. Pepperell JC, Casadei B, Craig S, Crosthwaite N, Stradling JR, Davies RJ (2008) CPAP and measures of cardiovascular risk in males with OSAS. Eur Respir J 32: 1488-1496.

[31] Jaimchariyatam N, Rodriguez CL, Budur K (2010) Does CPAP treatment in mild obstructive sleep apnea affect blood pressure? Sleep Med 11: 837-842.

[32] Marrone O, Salvaggio A, Bue AL, Bonanno A, Riccobono L, Insalaco G, Bonsignore MR (2011) Blood pressure changes after automatic and fixed CPAP in obstructive sleep apnea: relationship with nocturnal sympathetic activity. Clin Exp Hypertens 33: 373-380.

[33] Phillips CL, Yang Q, Williams A, Roth M, Yee BJ, Hedner JA, Berend N, Grunstein RR (2007) The effect of short-term withdrawal from continuous positive airway pressure therapy on sympathetic activity and markers of vascular inflammation in subjects with obstructive sleep apnoea. J Sleep Res 16: 217-225.

[34] Foster GE, Hanly PJ, Ahmed SB, Beaudin AE, Pialoux V, Poulin MJ (2010) Intermittent hypoxia increases arterial blood pressure in humans through a Renin-Angiotensin system-dependent mechanism. Hypertension 56: 369-377.

[35] Phillips BG, Narkiewicz K, Pesek CA, Haynes WG, Dyken ME, Somers VK (1999) Effects of obstructive sleep apnea on endothelin-1 and blood pressure. J Hypertens 17: 61-66.

[36] Rey S, Del Rio R, Iturriaga R (2006) Contribution of endothelin-1 to the enhanced carotid body chemosensory responses induced by chronic intermittent hypoxia. Brain Res 108: 6152-6159.

[37] Drager LF, Bortolotto LA, Figueiredo AC, Krieger EM, Lorenzi-Filho G (2007) Effects of continuous positive airway pressure on early signs of atherosclerosis in obstructive sleep apnea. Am J Respir Crit Care Med 176: 706-712.

[38] Grote L, Kraiczi H, Hedner J (2000) Reduced $\alpha$ - and $\beta(2)$-adrenergic vascular response in patients with obstructive sleep apnea. Am J Respir Crit Care Med 162: 1480-1487.

[39] Morgan BJ (2007) Vascular consequences of intermittent hypoxia. Adv Exp Med Biol 618: 69-84.

[40] Ziegler MG, Milic M, Elayan H (2011) Cardiovascular Regulation in Obstructive Sleep Apnea. Drug Discov Today Dis Models 8: 155-160.

[41] Talman WT, Perrone MH \& Reis DJ (1981) Acute hypertension after the local injection of kainic acid into the nucleus tractus solitarii of rats. Circ Res 48: 292-298.

[42] Machado $\mathrm{BH}$ (2001) Neurotransmission of the cardiovascular reflexes in the nucleus tractus solitarii of awake rats. Ann N Y Acad Sci 940: 179-196.

[43] Boscan P, Allen AM, Paton JF (2001) Baroreflex inhibition of cardiac sympathetic outflow is attenuated by angiotensin II in the nucleus of the solitary tract. Neuroscience 103: 153-160.

[44] Biaggioni I, Whetsell WO, Jobe J, Nadeau JH (1994) Baroreflex failure in a patient with central nervous system lesions involving the nucleus tractus solitarii. Hypertension 23: 491-495. 
[45] Cooper VL, Pearson SB, Bowker CM, Elliott MW, Hainsworth R (2005) Interaction of chemoreceptor and baroreceptor reflexes by hypoxia and hypercapnia - a mechanism for promoting hypertension in obstructive sleep apnoea. J Physiol 568: 677-687.

[46] Urbano F, Roux F, Schindler J, Mohsenin V (2008) Impaired cerebral autoregulation in obstructive sleep apnea. J Appl Physiol 105: 1852-1857.

[47] Culebras A (2007) Cerebrovascular disease and the pathophysiology of obstructive sleep apnea. Curr Neurol Neurosci Rep 7: 173-179.

[48] Nishibayashi M, Miyamoto M, Miyamoto T, Suzuki K, Hirata K (2008) Correlation between severity of obstructive sleep apnea and prevalence of silent ennin ng cular lesions. J Clin Sleep Med 4: 242-247.

[49] Brickman AM, Reitz C, Luchsinger JA, Manly JJ, Schupf N, Muraskin J, DeCarli C, Brown TR, Mayeux $\mathrm{R}$ (2010) Long-term blood pressure fluctuation and ennin ng cular disease in an elderly cohort. Arch Neurol 67: 564-569.

[50] Somers VK, Dyken ME, Clary MP, Abboud FM (1995) Sympathetic neural mechanisms in obstructive sleep apnea. J Clin Invest 96: 1897-1904.

[51] Narkiewicz K, van de Borne PJ, Montano N, Dyken ME, Phillips BG, Somers VK (1998a) Contribution of tonic chemoreflex activation to sympathetic activity and blood pressure in patients with obstructive sleep apnea. Circulation 97: 943-945.

[52] Dyken ME, Yamada T, Glenn CL, Berger HA (2004) Obstructive sleep apnea associated with cerebral hypoxemia and death. Neurology 62: 491-493.

[53] Khoo SM, Mukherjee JJ, Phua J, Shi DX (2009) Obstructive sleep apnea presenting as recurrent cardiopulmonary arrest. Sleep Breath 13: 89-92.

[54] Hayakawa T, Terashima M, Kayukawa Y, Ohta T, Okada T (1996) Changes in cerebral oxygenation and hemodynamics during obstructive sleep apneas. Chest 109: 916-921.

[55] Rosenberger P, Schwab JM, Mirakaj V, Masekowsky E, Mager A, Morote-Garcia JC, Unertl K, Eltzschig HK (2009) Hypoxia-inducible factor-dependent induction of netrin-1 dampens inflammation caused by hypoxia. Nat Immunol 10: 195-202.

[56] Eltzschig HK, Abdulla P, Hoffman E, Hamilton KE, Daniels D, Schönfeld C, Löffler M, Reyes G, Duszenko M, Karhausen J, Robinson A, Westerman KA, Coe IR, Colgan SP (2005) HIF-1-dependent repression of equilibrative nucleoside transporter (ENT) in hypoxia. J Exp Med 202: 1493-505.

[57] Eltzschig HK, Carmeliet P (2011) Hypoxia and Inflammation. New England J Med 364: 656-665,

[58] Rae C, Bartlett DJ, Yang Q, Walton D, Denotti A, Sachinwalla T, Grunstein R (2009) Dynamic changes in brain bioenergetics during obstructive sleep apnea. J Cereb Blood Flow Metab 29: 1421-1428.

[59] Kawano Y, Tamura A, Kadota J (2012) Association between the severity of obstructive sleep apnea and the ratio of low-density lipoprotein cholesterol to high-density lipoprotein cholesterol. Metabolism 61: 186192.

[60] Jun J, Reinke C, Bedja D, Berkowitz D, Bevans-Fonti S, Li J, Barouch LA, Gabrielson K, Polotsky VY (2010) Effect of intermittent hypoxia on atherosclerosis in apolipoprotein E-deficient mice. Atherosclerosis 209: 381-386.

[61] Savransky V, Jun J, Li J, Nanayakkara A, Fonti S, Moser AB, Steele KE, Schweitzer MA, Patil SP, Bhanot S, Schwartz AR, Polotsky VY (2008) Dyslipidemia and atherosclerosis induced by chronic intermittent hypoxia are attenuated by deficiency of stearoyl coenzyme A desaturase. Circ Res 103: 11731180. 
[62] Drager LF, Polotsky VY, Lorenzi-Filho G (2011) Obstructive sleep apnea: an emerging risk factor for atherosclerosis. Chest 140: 534-542.

[63] Vgontzas AN, Papanicolaou DA, Bixler EO, Kales A, Tyson K, Chrousos GP (1997) Elevation of plasma cytokines in disorders of excessive daytime sleepiness: role of sleep disturbance and obesity. $J$ Clin Endocrinol Metab 82: 1313-1316.

[64] Dyugovskaya L, Lavie P, Lavie L (2002) Increased adhesion molecules expression and production of reactive oxygen species in leukocytes of sleep apnea patients. Am J Respir Crit Care Med 165: 934-939.

[65] Shamsuzzaman AS, Winnicki M, Lanfranchi P, Wolk R, Kara T, Accurso V, Somers VK (2002) Elevated C-reactive protein in patients with obstructive sleep apnea. Circulation 105: 2462-2464.

[66] Ohga E, Nagase T, Tomita T, Teramoto S, Matsuse T, Katayama H, Ouchi Y (1999) Increased levels of circulating ICAM-1, VCAM-1, and L-selectin in obstructive sleep apnea syndrome. J Appl Physiol 87: 10-14.

[67] Ohga E, Tomita T, Wada H, Yamamoto H, Nagase T, Ouchi Y (2003) Effects of obstructive sleep apnea on circulating ICAM-1, IL-8, and MCP-1. J Appl Physiol 94: 179-184.

[68] El-Solh AA, Mador MJ, Sikka P, Dhillon RS, Amsterdam D, Grant BJ (2002) Adhesion molecules in patients with coronary artery disease and moderate-to-severe obstructive sleep apnea. Chest 121: 15411547.

[69] Jelic S, Le Jemtel TH (2008) Inflammation, oxidative stress, and the vascular endothelium in obstructive sleep apnea. Trends Cardiovasc Med 18: 253-260.

[70] Jelic S, Lederer DJ, Adams T, Padeletti M, Colombo PC, Factor PH, Le Jemtel TH (2010) Vascular inflammation in obesity and sleep apnea. Circulation 121: 1014-1021.

[71] Lurie A (2011) Endothelial dysfunction in adults with obstructive sleep apnea. Adv Cardiol 46: 139170.

[72] Kohler M, Stradling JR (2010) Mechanisms of vascular damage in obstructive sleep apnea. Nat Rev Cardiol 7: 677-685.

[73] Firat Guven S, Turkkani MH, Ciftci B, Ulukavak Ciftci T, Erdogan Y (2012) The relationship between high-sensitivity C-reactive protein levels and the severity of obstructive sleep apnea. Sleep Breath 16: 217221.

[74] Mausbach BT, Ancoli-Israel S, von Känel R, Patterson TL, Aschbacher K, Mills PJ, Ziegler MG, Dimsdale JE, Calleran S, Grant I (2006) Sleep disturbance, norepinephrine, and D-dimer are all related in elderly caregivers of people with Alzheimer disease. Sleep 29: 1347-1352.

[75] von Känel R, Dimsdale JE, Ancoli-Israel S, Mills PJ, Patterson TL, McKibbin CL, Archuleta C, Grant I (2006) Poor sleep is associated with higher plasma proinflammatory cytokine interleukin-6 and procoagulant marker fibrin D-dimer in older caregivers of people with Alzheimer's disease. J Am Geriatr Soc 54: 431437.

[76] von Känel R, Loredo JS, Ancoli-Israel S, Mills PJ, Natarajan L, Dimsdale JE (2007) Association between polysomnographic measures of disrupted sleep and prothrombotic factors. Chest 131: 733-739.

[77] Venugopal SK, Devaraj S, Yuhanna I, Shaul P, Jialal I (2002) Demonstration that C-reactive protein decreases eNOS expression and bioactivity in human aortic endothelial cells. Circulation 106: 1439-1441.

[78] Woollard KJ, Phillips DC, Griffiths HR (2002) Direct modulatory effect of C-reactive protein on primary human monocyte adhesion to human endothelial cells. Clin Exp Immunol 130: 256-262.

[79] Giunta B, Fernandez F, Nikolic WV, Obregon D, Rrapo E, Town T, Tan J (2008) Inflammaging as a prodrome to Alzheimer's disease. J Neuroinflammation 5: 51. 
[80] Büchner NJ, Quack I, Woznowski M, Stähle C, Wenzel U, Rump LC (2011) Microvascular endothelial dysfunction in obstructive sleep apnea is caused by oxidative stress and improved by continuous positive airway pressure therapy. Respiration 82: 409-417.

[81] Ramar K, Caples SM (2011) Vascular changes, cardiovascular disease and obstructive sleep apnea. Future Cardiol 7: 241-249.

[82] Dilger RN, Johnson RW (2008) Aging, microglial cell priming, and the discordant central inflammatory response to signals from the peripheral immune system. J Leukoc Biol 84: 932-939.

[83] Henry CJ, Huang Y, Wynne AM, Godbout JP (2009) Peripheral lipopolysaccharide (LPS) challenge promotes microglial hyperactivity in aged mice that is associated with exaggerated induction of both proinflammatory IL-1beta and anti-inflammatory IL-10 cytokines. Brain Behav Immun 23: 309-317.

[84] Holmes C, Cunningham C, Zotova E, Woolford J, Dean C, Kerr S, Culliford D, Perry VH (2009) Systemic inflammation and disease progression in Alzheimer disease. Neurology 73: 768-774.

[85] Oga T, Chin K, Tabuchi A, Kawato M, Morimoto T, Takahashi K, Handa T, Takahashi K, Taniguchi R, Kondo H, Mishima M, Kita T, Horiuchi H (2009) Effects of obstructive sleep apnea with intermittent hypoxia on platelet aggregability. J Atheroscler Thromb 16: 862-869.

[86] Rahangdale S, Yeh SY, Novack V, Stevenson K, Barnard MR, Furman MI, Frelinger AL, Michelson AD, Malhotra A (2011) The influence of intermittent hypoxemia on platelet activation in obese patients with obstructive sleep apnea. J Clin Sleep Med 7: 172-178.

[87] Nurden AT (2011) Platelets, inflammation and tissue regeneration. Thromb Haemost 105 (Suppl 1): S13-S33.

[88] Casoli T, Di Stefano G, Balietti M, Solazzi M, Giorgetti B, Fattoretti P (2010) Peripheral inflammatory biomarkers of Alzheimer's disease: the role of platelets. Biogerontology 11: 627-633.

[89] Casoli T, Di Stefano G, Giorgetti B, Grossi Y, Balietti M, Fattoretti P, Bertoni-Freddari C (2007) Release of beta-amyloid from high-density platelets: implications for Alzheimer's disease pathology. Ann $N Y$ Acad Sci 1096: 170-178.

[90] Ip MS, Tse HF, Lam B, Tsang KW, Lam WK (2004) Endothelial function in obstructive sleep apnea and response to treatment. Am J Respir Crit Care Med 169: 348-353.

[91] Patt BT, Jarjoura D, Haddad DN, Sen CK, Roy S, Flavahan NA, Khayat RN (2010) Endothelial dysfunction in the microcirculation of patients with obstructive sleep apnea. Am J Respir Crit Care Med 182: 1540-1545.

[92] Lavie L, Vishnevsky A, Lavie P (2004) Evidence for lipid peroxidation in obstructive sleep apnea. Sleep 27: $123-128$.

[93] Khayat R, Patt B, Hayes D Jr (2009) Obstructive sleep apnea: the new cardiovascular disease. Part I: Obstructive sleep apnea and the pathogenesis of vascular disease. Heart Fail Rev 14: 143-153.

[94] Förstermann U (2010) Nitric oxide and oxidative stress in vascular disease. Pflugers Arch 459: 923-939.

[95] Li J, Savransky V, Nanayakkara A, Smith PL, O’Donnell CP, Polotsky VY (2007) Hyperlipidemia and lipid peroxidation are dependent on the severity of chronic intermittent hypoxia. J Appl Physiol 102: 557-563.

[96] Kamba M, Inoue Y, Higami S, Suto Y, Ogawa T, Chen W (2001) Cerebral metabolic impairment in patients with obstructive sleep apnoea: an independent association of obstructive sleep apnoea with white matter change. J Neurol Neurosurg Psychiatry 71: 334-339. 
[97] Raji CA, Lopez OL, Kuller LH, Carmichael OT, Longstreth WT Jr, Gach HM, Boardman J, Bernick CB, Thompson PM, Becker JT (2012) White matter lesions and brain gray matter volume in cognitively normal elders. Neurobiol Aging 33: 834.e7-834.e16.

[98] Macey PM, Kumar R, Woo MA, Valladares EM, Yan-Go FL, Harper RM (2008) Brain structural changes in obstructive sleep apnea. Sleep 31: 967-977.

[99] Saunamäki T, Himanen SL, Polo O, Jehkonen M (2009) Executive dysfunction in patients with obstructive sleep apnea syndrome. Eur Neurol 62: 237-242.

[100] Antonelli Incalzi R, Marra C, Salvigni BL, Petrone A, Gemma A, Selvaggio D, Mormile F (2004) Does cognitive dysfunction conform to a distinctive pattern in obstructive sleep apnea syndrome? J Sleep Res 13: 79-86.

[101] Torelli F, Moscufo N, Garreffa G, Placidi F, Romigi A, Zannino S, Bozzali M, Fasano F, Giulietti G, Djonlagic I, Malhotra A, Marciani MG, Guttmann CR (2011) Cognitive profile and brain morphological changes in obstructive sleep apnea. Neuroimage 54: 787-793.

[102] Ancoli-Israel S, Palmer BW, Cooke JR, Corey-Bloom J, Fiorentino L, Natarajan L, Liu L, Ayalon L, He F, Loredo JS (2008) Cognitive effects of treating obstructive sleep apnea in Alzheimer's disease: a randomized controlled study. J Am Geriatr Soc 56: 2076-2081.

[103] Weaver TE, Chasens ER (2007) Continuous positive airway pressure treatment for sleep apnea in older adults. Sleep Med Rev 11: 99-111.

[104] Canessa N, Castronovo V, Cappa SF, Aloia MS, Marelli S, Falini A, Alemanno F, Ferini-Strambi L (2011) Obstructive sleep apnea: brain structural changes and neurocognitive function before and after treatment. Am J Respir Crit Care Med 183: 1419-1426.

[105] Lau EY, Eskes GA, Morrison DL, Rajda M, Spurr KF (2010) Executive function in patients with obstructive sleep apnea treated with continuous positive airway pressure. J Int Neuropsychol Soc 16: 10771088.

[106] Andresen MC, Kunze DL (1994) Nucleus tractus solitarius-gateway to neural circulatory control. Annu Rev Physiol 56: 93-116.

[107] Maier SF, Goehler LE, Fleshner M, Watkins LR (1998) The role of the vagus nerve in cytokine-tobrain communication, Ann NY Acad Sci 840: 289-300.

[108] Groves DA, Brown, VJ (2005) Vagal nerve stimulation: a review of its applications and potential mechanisms that mediate its clinical effects. Neurosci Biobehav Rev 29: 493-500.

[109] Celle S, Peyron R, Faillenot I, Pichot V, Alabdullah M, Gaspoz JM, Laurent B, Barthélémy JC, Roche F (2009) Undiagnosed sleep-related breathing disorders are associated with focal brainstem atrophy in the elderly. Hum Brain Mapp 30: 2090-2097.

[110] Daulatzai, MA (2010b) Conversion of elderly to Alzheimer's dementia: role of confluence of hypothermia and senescent stigmata—the plausible pathway. J Alzheimers Dis 21: 1039-1063.

[111] Pascual O, Morin-Surun MP, Barna B, Denavit-Saubié M, Pequignot JM, Champagnat J (2002) Progesterone reverses the neuronal responses to hypoxia in rat nucleus tractus solitarius in vitro. $\mathrm{J}$ Physiol 544: 511-520.

[112] Kline DD, Ramirez-Navarro A, Kunze DL (2007) Adaptive depression in synaptic transmission in the nucleus of the solitary tract after in vivo chronic intermittent hypoxia: evidence for homeostatic plasticity. $J$ Neurosci 27: 4663-4673. 
[113] Zhang JH, Fung SJ, Xi M, Sampogna S, Chase MH (2009) Recurrent apnea induces neuronal apoptosis in the guinea pig forebrain. Exp Neurol 216: 290-294.

[114] Kaur C, Viswanathan S, Ling EA (2011) Hypoxia-induced cellular and vascular changes in the nucleus tractus solitarius and ventrolateral medulla. J Neuropathol Exp Neurol 70: 201-217.

[115] Xu W, Chi L, Row BW, Xu R, Ke Y, Xu B, Luo C, Kheirandish L, Gozal D, Liu R (2004) Increased oxidative stress is associated with chronic intermittent hypoxia-mediated brain cortical neuronal cell apoptosis in a mouse model of sleep apnea. Neuroscience 126: 313-323.

[116] Machaalani R, Waters KA (2003) Increased neuronal cell death after intermittent hypercapnic hypoxia in the developing piglet brainstem. Brain Res 985: 127-134.

[117] Buller KM, Wixey JA, Pathipati P, Carty M, Colditz PB, Williams CE, Scheepens A (2008) Selective losses of brainstem catecholamine neurons after hypoxia-ischemia in the immature rat pup. Pediatr Res 63 : 364-369.

[118] Zhang JH, Fung SJ, Xi M, Sampogna S, Chase MH (2010) Apnea produces neuronal degeneration in the pons and medulla of guinea pigs. Neurobiol Dis 40: 251-264.

[119] Stecco C, Porzionato A, Macchi V, Sarasin G, Calcagno A, Parenti A, De Caro R (2005) Detection of apoptosis in human brainstem by TUNEL assay. Ital J Anat Embryol 110: 255-260.

[120] De Caro R, Parenti A, Montisci M, Guidolin D, Macchi V (2000) Solitary Tract Nuclei in Acute Heart Failure. Stroke 31: 1187-1193.

[121] Lièvre V, Becuwe $P$, Bianchi A, Bossenmeyer-Pourié $C$, Koziel V, Franck $P$, Nicolas MB, Dauça M, Vert P, Daval JL (2001) Intracellular generation of free radicals and modifications of detoxifying enzymes in cultured neurons from the developing rat forebrain in response to transient hypoxia. Neuroscience 105: 287-297.

[122] Tan ZS, Seshadri S (2010) Inflammation in the Alzheimer's disease cascade: culprit or innocent bystander? Alzheimers Res Ther 2: 6.

[123] Agostinho P, Cunha RA, Oliveira C(2010) Neuroinflammation, oxidative stress and the pathogenesis of Alzheimer's disease. Curr Pharm Des 16: 2766-2778.

[124] Rogers J, Mastroeni D, Leonard B, Joyce J, Grover A (2007) Neuroinflammation in Alzheimer's disease and Parkinson's disease: are microglia pathogenic in either disorder? Int Rev Neurobiol 82: 235246.

[125] Sirivelu MP, MohanKumar PS, MohanKumar SM (2012) Differential effects of systemic interleukin-1 $\beta$ on gene expression in brainstem noradrenergic nuclei. Life Sci 90: 77-81.

[126] Moalem G, Tracey DJ (2006) Immune and inflammatory mechanisms in neuropathic pain. Brain Res Rev 51: 240-264.

[127] Del Rio R, Moya EA, Parga MJ, Madrid C, Iturriaga R (2011) Carotid body inflammation and cardiorespiratory alterations in intermittent hypoxia. Eur Respir J Dec 19. [Epub ahead of print].

[128] Stanimirovic D, Shapiro A, Wong J, Hutchison J, Durkin JP (1997) The induction of ICAM-1 in human cerebromicrovascular endothelial cells (HCEC) by ischemia-like conditions promotes enhanced neutrophil/HCEC adhesion. J Neuroimmunol 76: 193-205.

[129] Kim KS, Rajagopal V, Gonsalves C, Johnson C, Kalra VK (2006) A novel role of hypoxia-inducible factor in cobalt chloride- and hypoxia-mediated expression of IL-8 chemokine in human endothelial cells. J Immunol 177: 7211-7224. 
[130] Zhang W, Smith C, Howlett C, Stanimirovic D (2000) Inflammatory activation of human brain endothelial cells by hypoxic astrocytes in vitro is mediated by IL-1 $\beta$. J Cereb Blood Flow Metab 20: 967978.

[131] Zhang W, Mojsilovic-Petrovic J, Callaghan D, Jones A, Cui H, Howlett C, Stanimirovic D (2006) Evidence that hypoxia-inducible factor-1 (HIF-1) mediates transcriptional activation of Interleukin-1 $\beta$ (IL-1 $\beta$ ) in astrocyte cultures. J Neuroimmunol 174: 63-73

[132] Mojsilovic-Petrovic J, Callaghan D, Cui H, Dean C, Stanimirovic DB, Zhang W (2007) Hypoxiainducible factor-1 (HIF-1) is involved in the regulation of hypoxia-stimulated expression of monocyte chemoattractant protein-1 (MCP-1/CCL2) and MCP-5 (Ccl12) in astrocytes. J Neuroinflammation 4: 12.

[133] Csiszar A, Wang M, Lakatta EG, Ungvari Z ( ) Inflammation and endothelial dysfunction during aging: role of NF-kappaB. J Appl Physiol 105: 1333-1341.

[134] Fogal B, Li J, Lobner D, McCullough LD, Hewett SJ (2007) System xl- activity and astrocytes are necessary for interleukin-1 beta-mediated hypoxic neuronal injury. J Neurosci 27: 10094-10105.

[135] Ng KM, Lau CF, Fung ML (2010) Melatonin reduces hippocampal beta-amyloid generation in rats exposed to chronic intermittent hypoxia. Brain Res 1354: 163-171.

[136] Waki H, Gouraud SS, Maeda M, Paton JF (2010) Evidence of specific inflammatory condition in nucleus tractus solitarii of spontaneously hypertensive rats. Exp Physiol 95: 595-600.

[137] Waki H, Bhuiyan ME, Gouraud SS, Takagishi M, Hatada A, Kohsaka A, Paton JF, Maeda M (2011) Acute reductions in blood flow restricted to the dorsomedial medulla induce a pressor response in rats. $J$ Hypertens 29: 1536-1545.

[138] Colton CA, Mott RT, Sharpe H, Xu Q, Van Nostrand WE, Vitek MP (2006) Expression profiles for macrophage alternative activation genes in $A D$ and in mouse models of AD. J Neuroinflammation 27: 27.

[139] Rathcke CN, Vestergaard H (2006) YKL-40, a new inflammatory marker with relation to insulin resistance and with a role in endothelial dysfunction and atherosclerosis. Inflamm Res 55: 221-227.

[140] Paton JF, Waki H (2009) Is neurogenic hypertension related to vascular inflammation of the brainstem? Neurosci Biobehav Rev 33: 89-94.

[141] Nieto FJ, Young TB, Lind BK, Shahar E, Samet JM, Redline S, D’Agostino RB, Newman AB, Lebowitz MD, Pickering TG (2000) Association of sleep-disordered breathing, sleep apnea, and hypertension in a large community-based study. Sleep Heart Health Study. JAMA 283: 1829-1836.

[142] Can I, Aytemir K, Demir AU, Deniz A, Ciftci O, Tokgozoglu L, Oto A, Sahin A (2009) P-wave duration and dispersion in patients with obstructive sleep apnea. Int J Cardiol 133: e85-e89.

[143] Sari I, Davutoglu V, Ozbala B, Ozer O, Baltaci Y, Yavuz S, Aksoy M (2008) Acute sleep deprivation is associated with increased electrocardiographic $p$-wave dispersion in healthy young men and women. Pacing Clin Electrophysiol 31: 438-442.

[144] Hung J, Whitford EG, Parsons RW, Hillman DR (1990) Association of sleep apnoea with myocardial infarction in men. Lancet 336: 261-264.

[145] Peled N, Abinader EG, Pillar G, Sharif D, Lavie P (1999) Nocturnal ischemic events in patients with obstructive sleep apnea syndrome and ischemic heart disease: effects of continuous positive air pressure treatment. J Am Coll Cardiol 34: 1744-1749.

[146] Peker Y, Hedner J, Kraiczi H, Löth S (2000) Respiratory disturbance index: an independent predictor of mortality in coronary artery disease. Am J Respir Crit Care Med 162: 81-86. 
[147] Vgontzas AN, Zoumakis M, Papanicolaou DA, Bixler EO, Prolo P, Lin HM, Vela-Bueno A, Kales A, Chrousos GP (2002) Chronic insomnia is associated with a shift of interleukin-6 and tumor necrosis factor secretion from nighttime to daytime. Metabolism 51: 887-892.

[148] Hanly P, Sasson Z, Zuberi N, Lunn K (1993) ST-segment depression during sleep in obstructive sleep apnea. Am J Cardiol 71: 1341-1345.

[149] Franklin KA, Nilsson JB, Sahlin C, Naslund U (1995) Sleep apnoea and nocturnal angina. Lancet 345: 1085-1087.

[150] Philip P, Guilleminault C (1993) ST segment abnormality, angina during sleep and obstructive sleep apnea. Sleep 16: 558-559.

[151] Lau DH, Mackenzie L, Kelly DJ, Psaltis PJ, Worthington M, Rajendram A, Kelly DR, Nelson AJ, Zhang Y, Kuklik P, Brooks AG, Worthley SG, Faull RJ, Rao M, Edwards J, Saint DA, Sanders P (2010) Short-term hypertension is associated with the development of atrial fibrillation substrate: a study in an ovine hypertensive model. Heart Rhythm 7: 396-404.

[152] Lisman KA, Stetson SJ, Koerner MM, Farmer JA, Torre-Amione G (2002) The role of inflammation in the pathogenesis of heart failure. Curr Cardiol Rep 4: 200-205.

[153] Schulz R, Schmidt D, Blum A, Lopes-Ribeiro X, Lücke C, Mayer K, Olschewski H, Seeger W, Grimminger F (2000) Decreased plasma levels of nitric oxide derivatives in obstructive sleep apnoea: response to CPAP therapy. Thorax 55: 1046-1051.

[154] Kato M, Roberts-Thomson P, Phillips BG, Haynes WG, Winnicki M, Accurso V, Somers VK (2000) Impairment of endothelium-dependent vasodilation of resistance vessels in patients with obstructive sleep apnea. Circulation 102: 2607-2610.

[155] Poredos P, Orehek M, Tratnik E (1999) Smoking is associated with dose-related increase of intimamedia thickness and endothelial dysfunction. Angiology 50: 201-208.

[156] Lee IK, Kim HS, Bae JH (2002) Endothelial dysfunction: its relationship with acute hyperglycaemia and hyperlipidemia. Int J Clin Pract Suppl 129: 59-64.

[157] Rizzoni D, Porteri E, Guelfi D, Muiesan ML, Piccoli A, Valentini U, Cimino A, Girelli A, Salvetti M, De Ciuceis C, Tiberio GA, Giulini SM, Sleiman I, Monteduro C, Rosei EA (2001) Endothelial dysfunction in small resistance arteries of patients with non-insulin-dependent diabetes mellitus. J Hypertens 19: 913919.

[158] Yim-Yeh S, Rahangdale S, Nguyen AT, Jordan AS, Novack V, Veves A, Malhotra A (2010) Obstructive sleep apnea and aging effects on macrovascular and microcirculatory function. Sleep 33: 1177-1183.

[159] Yim-Yeh S, Rahangdale S, Nguyen AT, Stevenson KE, Novack V, Veves A, Malhotra A (2011) Vascular dysfunction in obstructive sleep apnea and type 2 diabetes mellitus. Obesity (Silver Spring) 19: 17-22.

[160] Buchner NJ, Quack I, Stegbauer J, Woznowski M, Kaufmann A, Rump LC (2012) Treatment of obstructive sleep apnea reduces arterial stiffness. Sleep Breath 16: 123-133.

[161] Henning EC, Warach S, Spatz M (2010) Hypertension-induced vascular remodeling contributes to reduced cerebral perfusion and the development of spontaneous stroke in aged SHRSP rats. J Cereb Blood Flow Metab 30: 827-836.

[162] Johansson BB (1984) Cerebral vascular bed in hypertension and consequences for the brain. Hypertension 6: III81-III86.

[163] Bålfors EM, Franklin KA (1994) Impairment of cerebral perfusion during obstructive sleep apneas. Am J Respir Crit Care Med 150: 1587-1591. 
[164] Farkas E, De Vos RA, Jansen Steur EN, Luiten PG (2000) Are Alzheimer's disease, hypertension, and cerebrocapillary damage related?. Neurobiol Aging 21: 235-243.

[165] Israeli-Korn SD, Masarwa M, Schechtman E, Abuful A, Strugatsky R, Avni S, Farrer LA, Friedland RP, Inzelberg R (2010) Hypertension increases the probability of Alzheimer's disease and of mild cognitive impairment in an Arab community in northern Israel. Neuroepidemiology 34: 99-105.

[166] Yang YH, Roe CM, Morris JC (2011) Relationship between late-life hypertension, blood pressure, and Alzheimer's disease. Am J Alzheimers Dis Other Demen 26: 457-462.

[167] Corfield DR, Meadows GE (2006) Control of cerebral blood flow during sleep and the effects of hypoxia. Adv Exp Med Biol 588: 65-73.

[168] Olopade CO, Mensah E, Gupta R, Huo D, Picchietti DL, Gratton E, Michalos A (2007) Noninvasive determination of brain tissue oxygenation during sleep in obstructive sleep apnea: a near-infrared spectroscopic approach. Sleep 30: 1747-1755.

[169] Namtvedt SK, Randby A, Einvik G, Hrubos-Strøm H, Somers VK, Røsjø H, Omland T (2011) Cardiac arrhythmias in obstructive sleep apnea (from the Akershus Sleep Apnea Project). Am J Cardiol 108: 11411146.

[170] Won CH, Chun HJ, Chandra SM, Sarinas PS, Chitkara RK, Heidenreich PA (2012) Severe obstructive sleep apnea increases mortality in patients with ischemic heart disease and myocardial injury. Sleep Breath Feb 1. [Epub ahead of print].

[171] Foster GE, Poulin MC, Hanly PJ (2007) Intermittent hypoxia and vascular function: implications for obstructive sleep apnoea

Exp Physiol 92: 51-65.

[172] Furtner M, Staudacher M, Frauscher B, Brandauer E, Esnaola y Rojas MM, Gschliesser V, Poewe W, Schmidauer C, Ritsch-Marte M, Högl B (2009) Cerebral vasoreactivity decreases overnight in severe obstructive sleep apnea syndrome: a study of cerebral hemodynamics. Sleep Med 10: 875-881.

[173] Hsieh SW, Lai CL, Liu CK, Hsieh CF, Hsu CY (2012) Obstructive sleep apnea linked to wake-up strokes. J Neurol Jan 4. [Epub ahead of print].

[174] Cheng Z, Guo SZ, Lipton AJ, Gozal D (2002) Domoic acid lesions in nucleus of the solitary tract: timedependent recovery of hypoxic ventilatory response and peripheral afferent axonal plasticity. J Neurosci 22 : 3215-3226.

[175] Snowdon DA, Greiner LH, Mortimer JA, Riley KP, Greiner PA, Markesbery WR (1997) Brain infarction and the clinical expression of Alzheimer's disease: the nun study. JAMA 277:813-817.

[176] Jellinger KA, Attems J (2007) Neuropathological evaluation of mixed dementia. J Neurol Sci 257: 8087.

[177] Jefferson AL, Himali JJ, Au R, Seshadri S, Decarli C, O’Donnell CJ, Wolf PA, Manning WJ, Beiser AS, Benjamin EJ (2011) Relation of left ventricular ejection fraction to cognitive aging from the Framingham Heart Study. Am J Cardiol 108: 1346 -1351.

[178] Kume K, Hanyu H, Sato T, Hirao K, Shimizu S, Kanetaka H, Sakurai H, Iwamoto T (2011) Vascular risk factors are associated with faster decline of Alzheimer disease: a longitudinal SPECT study. J Neurol 258: 1295-1303.

[179] van Beek AH, Lagro J, Olde-Rikkert MG, Zhang R, Claassen JA (2012) Oscillations in cerebral blood flow and cortical oxygenation in Alzheimer's disease. Neurobiol Aging 33: 428.e21-e31.

[180] Okamoto Y, Yamamoto T, Kalaria RN, Senzaki H, Maki T, Hase Y, Kitamura A, Washida K, Yamada $\mathrm{M}$, Ito $\mathrm{H}$, Tomimoto $\mathrm{H}$, Takahashi $\mathrm{R}$, Ihara $\mathrm{M}$ (2012) Cerebral hypoperfusion accelerates cerebral amyloid angiopathy and promotes cortical microinfarcts. Acta Neuropathol 123: 381-394. 
[181] Soontornniyomkij V, Lynch MD, Mermash S Pomakian J, Badkoobehi H, Clare R, Vinters HV (2010) Cerebral microinfarcts associated with severe cerebral beta-amyloid angiopathy. Brain Pathol 20: 459-467

[182] de la Torre JC (2000) Critically attained threshold of cerebral hypoperfusion: can it cause Alzheimer's disease? Ann N Y Acad Sci 903: 424-436.

[183] Sun X, He G, Qing H, Zhou W, Dobie F, Cai F, Staufenbiel M, Huang LE, Song W (2006) Hypoxia facilitates Alzheimer's disease pathogenesis by up-regulating BACE1 gene expression. Proc Natl Acad Sci U S A 103: 18727-18732.

[184] Murray IV, Proza JF, Sohrabji F, Lawler JM (2011) Vascular and metabolic dysfunction in Alzheimer's disease: a review. Exp Biol Med (Maywood) 236: 772-782.

[185] Kalaria RN, Bhatti SU, Lust WD, Perry G (1993) The amyloid precursor protein in ischemic brain injury and chronic hypoperfusion. Ann N Y Acad Sci 695: 190-193.

[186] Sadowski M, Pankiewicz J, Scholtzova H, Li YS, Quartermain D, Duff K, Wisniewski T (2004) Links between the pathology of Alzheimer's disease and vascular dementia. Neurochem Res 29: 1257-1266.

[187] Wang X, Xing A, Xu C, Cai Q, Liu H, Li L (2010) Cerebrovascular hypoperfusion induces spatial memory impairment, synaptic changes, and amyloid- $\beta$ oligomerization in rats. J Alzheimers Dis 21: 813822.

[188] Sun MK, Alkon DL (2004) Cerebral hypoperfusion and amyloid-induced synergistic impairment of hippocampal CA1 synaptic efficacy and spatial memory in young adult rats. J Alzheimers Dis 6: $355-366$.

[189] Liu H, Xing A, Wang X, Liu G, Li L (2012) Regulation of $\beta$-amyloid level in the brain of rats with ennin ng cular hypoperfusion. Neurobiol Aging 33: 826.e31-e42.

[190] Ip MS, Lam B, Ng MM, Lam WK, Tsang KW, Lam KS (2002) Obstructive sleep apnea is independently associated with insulin resistance. Am J Respir Crit Care Med 165: 670-676.

[191] Spiegel K, Knutson K, Leproult R, Tasali E, Van Cauter E (2005) Sleep loss: a novel risk factor for insulin resistance and Type 2 diabetes. J Appl Physiol 99: 2008-2019.

[192] Spiegel K, Tasali E, Leproult R, Van Cauter E (2009) Effects of poor and short sleep on glucose metabolism and obesity risk. Nat Rev Endocrinol 5, 253-261.

[193] Ronksley PE, Hemmelgarn BR, Heitman SJ, Hanly PJ, Faris PD, Quan H, Tsai WH (2009) Obstructive sleep apnoea is associated with diabetes in sleepy subjects. Thorax 64: 834-839.

[194] Morselli L, Leproult R, Balbo M, Spiegel K (2010) Role of sleep duration in the regulation of glucose metabolism and appetite. Best Pract Res Clin Endocrinol Metab 24: 687-702.

[195] Nena E, Steiropoulos P, Papanas N, Tsara V, Fitili C, Froudarakis ME, Maltezos E, Bouros D (2012) Sleepiness as a marker of glucose deregulation in obstructive sleep apnea. Sleep Breath 16: 181-186.

[196] Punjabi NM, Shahar E, Redline S, Gottlieb DJ, Givelber R, Resnick HE (2004) Sleep Heart Health Study Investigators. Sleep-disordered breathing, glucose intolerance, and insulin resistance: the Sleep Heart Health Study. Am J Epidemiol 160: 521-530.

[197] Elmasry A, Lindberg E, Berne C, Janson C, Gislason T, Awad Tageldin M, Boman G (2001) Sleepdisordered breathing and glucose metabolism in hypertensive men: a population-based study. J Intern Med 249: 153-161.

[198] Tamura A, Kawano Y, Watanabe T, Kadota J (2008) Relationship between the severity of obstructive sleep apnea and impaired glucose metabolism in patients with obstructive sleep apnea. Respir Med 102: 1412-1416. 
[199] Pamidi S, Aronsohn RS, Tasali E (2010) Obstructive sleep apnea: role in the risk and severity of diabetes. Best Pract Res Clin Endocrinol Metab 24: 703-715.

[200] Pandey A, Demede M, Zizi F, Al Haija'a OA, Nwamaghinna F, Jean-Louis G, McFarlane SI (2011) Sleep apnea and diabetes: insights into the emerging epidemic. Curr Diab Rep 11: 35-40.

[201] liyori N, Alonso LC, Li J, Sanders MH, Garcia-Ocana A, O’Doherty RM, Polotsky VY, O’Donnell CP (2007) Intermittent hypoxia causes insulin resistance in lean mice independent of autonomic activity. Am J Respir Crit Care Med 175: 851-857.

[202] Bertuglia S, Reiter RJ (2009) Melatonin reduces microvascular damage and insulin resistance in hamsters due to chronic intermittent hypoxia. J Pineal Res 46: 307-313.

[203] Brooks B, Cistulli PA, Borkman M, Ross G, McGhee S, Grunstein RR, Sullivan CE, Yue DK (1994) Obstructive sleep apnea in obese noninsulin-dependent diabetic patients: effect of continuous positive airway pressure treatment on insulin responsiveness. Clin Endocrinol Metab 79: 1681-1685.

[204] Dawson A, Abel SL, Loving RT, Dailey G, Shadan FF, Cronin JW, Kripke DF, Kline LE (2008) CPAP therapy of obstructive sleep apnea in type 2 diabetics improves glycemic control during sleep. J Clin Sleep Med 4: 538-542.

[205] Lam JC, Tan KC, Lai AY, Lam DC, Ip MS (2012) Increased serum levels of advanced glycation endproducts is associated with severity of sleep disordered breathing but not insulin sensitivity in non-diabetic men with obstructive sleep apnoea. Sleep Med 13: 15-20.

[206] Peltier AC, Bagai K, Artibee K, Diedrich A, Garland E, Elasy T, Shi Y, Wang L, Feldman EL, Robertson D, Malow BA (2012) Effect of mild hyperglycemia on autonomic function in obstructive sleep apnea. Clin Auton Res 22: 1-8.

[207] Drager LF, Jun JC, Polotsky VY (2010) Metabolic consequences of intermittent hypoxia: relevance to obstructive sleep apnea. Best Pract Res Clin Endocrinol Metab 24: 843-851.

[208] Deboer MD, Mendoza JP, Liu L, Ford G, Yu PL, Gaston BM (2011) Increased systemic inflammation overnight correlates with insulin resistance among children evaluated for obstructive sleep apnea. Sleep Breath Mar 1 [Epub ahead of print].

[209] Knutson KL, Van Cauter E (2008;) Associations between sleep loss and increased risk of obesity and diabetes. Ann N Y Acad Sci 1129: 287-304.

[210] Harsch IA, Schahin SP, Brückner K, Radespiel-Tröger M, Fuchs FS, Hahn EG, Konturek PC, Lohmann T, Ficker JH (2004) The effect of continuous positive airway pressure treatment on insulin sensitivity in patients with obstructive sleep apnoea syndrome and type 2 diabetes. Respiration 71: 252259.

[211] Hassaballa HA, Tulaimat A, Herdegen JJ, Mokhlesi B (2005) The effect of continuous positive airway pressure on glucose control in diabetic patients with severe obstructive sleep apnea. Sleep Breath 9:176180.

[212] Leenders KL, Perani D, Lammertsma AA, Heather JD, Buckingham P, Healy MJ, Gibbs JM, Wise RJ, Hatazawa J, Herold S (1990) Cerebral blood flow, blood volume and oxygen utilization. Normal values and effect of age. Brain 113: 27-47.

[213] Bangen KJ, Restom K, Liu TT, Jak AJ, Wierenga CE, Salmon DP, Bondi MW (2009) Differential age effects on cerebral blood flow and BOLD response to encoding: associations with cognition and stroke risk. Neurobiol Aging 30: 1276-1287.

[214] Takada H, Nagata K, Hirata Y, Satoh Y, Watahiki Y, Sugawara J (1992) Age-related decline of cerebral oxygen metabolism in normal population detected with positron emission tomography. Neurol Res 14: 128-131. 
[215] Hoyer S (1982a) The young-adult and normally aged brain. Its blood flow and oxidative metabolism. A review-part I. Arch Gerontol Geriatr 1: 101-116.

[216] Powers WJ, Videen TO, Markham J, Walter V, Perlmutter JS (2011) Metabolic control of resting hemispheric cerebral blood flow is oxidative, not glycolytic. J Cereb Blood Flow Metab 31: 1223-1228.

[217] Claus JJ, Breteler MM, Hasan D, Krenning EP, Bots ML, Grobbee DE, Van Swieten JC, Van Harskamp F, Hofman A (1998) Regional cerebral blood flow and cerebrostroke risk factors in the elderly population, Neurobiol. Aging 19: 57-64.

[218] D'Esposito M, Deouell LY, Gazzaley A (2003) Alterations in the BOLD fMRI signal with ageing and disease: a challenge for neuroimaging. Nat Rev Neurosci 4: 863-872.

[219] Yamaguchi T, Kanno I, Uemura K, Shishido F, Inugami A, Ogawa T, Murakami M, Suzuki K (1986) Reduction in regional cerebral metabolic rate of oxygen during human aging. Stroke 17: 1220-1228.

[220] Hagstadius S, Risberg J (1989) Regional cerebral blood flow characteristics and variations with age in resting normal subjects. Brain Cogn 10: 28-43.

[221] Parkes LM, Rashid W, Chard DT, Tofts PS (2004) Normal cerebral perfusion measurements using arterial spin labeling: reproducibility, stability, and age and gender effects. Magn Reson Med 51: 736-743.

[222] Petit-Taboué MC, Landeau B, Desson JF, Desgranges B, Baron JC (1998) Effects of healthy aging on the regional cerebral metabolic rate of glucose assessed with statistical parametric mapping. Neuroimage 7: 176-184.

[223] Kadir A, Almkvist O, Forsberg A, Wall A, Engler H, Långström B, Nordberg A (2012) Dynamic changes in PET amyloid and FDG imaging at different stages of Alzheimer's disease. Neurobiol Aging 33: 198.e1198.e14.

[224] Klunk WE, Engler H, Nordberg A, Wang Y, Blomqvist G, Holt DP, Bergström M, Savitcheva I, Huang GF, Estrada S, Ausén B, Debnath ML, Barletta J, Price JC, Sandell J, Lopresti BJ, Wall A (2004) Imaging brain amyloid in Alzheimer's disease with Pittsburgh Compound-B. Ann Neurol 55: 306-319.

[225] Langbaum JB, Chen K, Launer LJ, Fleisher AS, Lee W, Liu X, Protas HD, Reeder SA, Bandy D, Yu M, Caselli RJ, Reiman EM (2012) Blood pressure is associated with higher brain amyloid burden and lower glucose metabolism in healthy late middle-age persons. Neurobiol Aging 33: 827.e11-827.e19.

[226] Zlokovic BV (2011) Neurovascular pathways to neurodegeneration in Alzheimer's disease and other disorders. Nat Rev Neurosci 12: 723-738.

[227] Muller M, van der Graaf Y, Visseren FL, Mali WP, Geerlings MI (2012) Hypertension and longitudinal changes in cerebral blood flow: The SMART-MR study. Ann Neurol Feb 3. doi: 10.1002/ana.23554. [Epub ahead of print].

[228] Hoyer S (1982) The abnormally aged brain. Its blood flow and oxidative metabolism. A review - part II. Arch Gerontol Geriatr 1: 195-207.

[229] Thal DR, Griffin WS, de Vos RA, Ghebremedhin E (2008) Cerebral amyloid angiopathy and its relationship to Alzheimer's disease. Acta Neuropathol 115: 599-609.

[230] Hunt A, Schönknecht P, Henze M, Seidl U, Haberkorn U, Schröder J (2007) Reduced cerebral glucose metabolism in patients at risk for Alzheimer's disease. Psychiatry Res 155: 147-154.

[231] Furst AJ, Lal RA (2011) Amyloid- $\beta$ and glucose metabolism in Alzheimer's disease. J Alzheimers Dis 26: Suppl 3: 105-116.

[232] Ishii H, Ishikawa H, Meguro K, Tashiro M, Yamaguchi S (2009) Decreased cortical glucose metabolism in converters from CDR 0.5 to Alzheimer's disease in a community: the Osaki-Tajiri Project. Int Psychogeriatr 21: 148-156. 
[233] Herholz K (2010) Cerebral glucose metabolism in preclinical and prodromal Alzheimer's disease. Expert Rev Neurother 10: 1667-1673.

[234] Mosconi L, Sorbi S, de Leon MJ, Li Y, Nacmias B, Myoung PS, Tsui W, Tsui W, Ginestroni A, Bessi V, Fayyazz M, Caffarra P, Pupi A (2006) Hypometabolism exceeds atrophy in presymptomatic early-onset familial Alzheimer's disease. J Nucl Med 47: 1778-1786.

[235] Mosconi L, De Santi S, Li J, Tsui WH, Li Y, Boppana M, Laska E, Rusinek H, de Leon MJ (2008) Hippocampal hypometabolism predicts cognitive decline from normal aging. Neurobiol Aging 29: 676-692.

[236] Drzezga A, Lautenschlager N, Siebner H, Riemenschneider M, Willoch F, Minoshima S, Schwaiger M, Kurz A (2003) Cerebral metabolic changes accompanying conversion of mild cognitive impairment into Alzheimer's disease: a PET follow-up study. Eur J Nucl Med Mol Imaging 30: 1104-1113.

[237] Mosconi L (2005) Brain glucose metabolism in the early and specific diagnosis of Alzheimer's disease. FDG-PET studies in MCl and AD. Eur J Nucl Med Mol Imaging 32: 486-510.

[238] Nestor PJ, Fryer TD, Smielewski P, Hodges JR (2003) Limbic hypometabolism in Alzheimer's disease and mild cognitive impairment. Ann Neurol 54: 343-351.

[239] Poisnel G, Hérard AS, El Tannir El Tayara N, Bourrin E, Volk A, Kober F, Delatour B, Delzescaux T, Debeir T, Rooney T, Benavides J, Hantraye P, Dhenain M (2011) Increased regional cerebral glucose uptake in an APP/PS1 model of Alzheimer's disease. Neurobiol Aging Nov 11. [Epub ahead of print].

[240] de la Monte SM (2012) Contributions of brain insulin resistance and deficiency in amyloid-related neurodegeneration in Alzheimer's disease. Drugs 72: 49-66.

[241] Craft S (2007) Insulin resistance and Alzheimer's disease pathogenesis: potential mechanisms and implications for treatment. Curr Alzheimer Res 4: 147-152.

[242] Neumann KF, Rojo L, Navarrete LP, Farías G, Reyes P, Maccioni RB (2008) Insulin resistance and Alzheimer's disease: molecular links and clinical implications. Curr Alzheimer Res 5: 438-447.

[243] Sroriz-Filho J, Sá-Roriz TM, Rosset I, Camozzato AL, Santos AC, Chaves ML, Moriguti JC, Roriz-Cruz M (2009) (Pre)diabetes, brain aging, and cognition. Biochim Biophys Acta 1792: 432-443.

[244] Sato N, Takeda S, Uchio-Yamada K, Ueda H, Fujisawa T, Rakugi H, Morishita R (2011) Role of insulin signaling in the interaction between Alzheimer disease and diabetes mellitus: a missing link to therapeutic potential. Curr Aging Sci 4: 118-127.

[245] Ding Y, Kantarci A, Hasturk H, Trackman PC, Malabanan A, Van Dyke TE (2007) Activation of RAGE induces elevated O2- generation by mononuclear phagocytes in diabetes. J Leukoc Biol 81: 520-527.

[246] Hallam KM, Li Q, Ananthakrishnan R, Kalea A, Zou YS, Vedantham S, Schmidt AM, Yan SF, Ramasamy $R$ (2010) Aldose reductase and AGE-RAGE pathways: central roles in the pathogenesis of vascular dysfunction in aging rats. Aging Cell 9: 776-784.

[247] Srikanth V, Maczurek A, Phan T, Steele M, Westcott B, Juskiw D, Münch G (2011) Advanced glycation endproducts and their receptor RAGE in Alzheimer's disease. Neurobiol Aging 32: 763-777.

[248] Freude S, Schilbach K, Schubert M (2009) The role of IGF-1 receptor and insulin receptor signaling for the pathogenesis of Alzheimer's disease: from model organisms to human disease. Curr Alzheimer Res 6: 213-223.

[249] Zemva J, Schubert M (2011) Central insulin and insulin-like growth factor-1 signaling: implications for diabetes associated dementia. Curr Diabetes Rev 7: 356-366. 
[250] Lester-Coll N, Rivera EJ, Soscia SJ, Doiron K, Wands JR, de la Monte SM (2006) Intracerebral streptozotocin model of type 3 diabetes: relevance to sporadic Alzheimer's disease. J Alzheimers Dis 9: 1333.

[251] Seigel GM, Lupien SB, Campbell LM, Ishii DN (2006) Systemic IGF-I treatment inhibits cell death in diabetic rat retina. J Diabetes Complications 20: 196-204.

[252] Mattson MP (1997) Cellular actions of beta-amyloid precursor protein and its soluble and fibrillogenic derivatives. Physiol Rev 77: 1081-1132.

[253] Desmond DW, Moroney JT, Sano M, Stern Y (2002) Incidence of dementia after ischemic stroke: results of a longitudinal study. Stroke 33: 2254-2260.

[254] Grammas P, Tripathy D, Sanchez A, Yin X, Luo J (2011) Brain microvasculature and hypoxia-related proteins in Alzheimer's disease. Int J Clin Exp Pathol 4: 616-627.

[255] Lee S-R, Lo EH (2004) Induction of caspase mediated cell death by matrix metalloproteinases in cerebral endothelial cells after hypoxia-reoxygenation. J Cereb Blood Flow Metab 24: 720-727.

[256] Egashira N, Iwasaki K, Ishibashi M, Hatip-Al-Khatib I, Wolozin B, Mishima K, Irie K, Fujiwara M (2002) Hypoxia enhances beta-amyloid-induced apoptosis in rat cultured hippocampal neurons. Jpn J Pharmacol 90: 321-327.

[257] Friedman JE, Chow EJ, Haddad GG (1998) State of actin filaments is changed by anoxia in cultured rat neocortical neurons. Neuroscience 82: 421-427.

[258] Breteler MM (2000) Vascular risk factors for Alzheimer's disease: an epidemiologic perspective. Neurobiol Aging 21: 153-160.

[259] de la Monte SM, Neely TR, Cannon J, Wands JR (2000) Oxidative stress and hypoxia-like injury cause Alzheimer-type molecular abnormalities in central nervous system neurons. Cell Mol Life Sci 57: 14711481.

[260] Emerit J, Edeas M, Bricaire F (2004) Neurodegenerative diseases and oxidative stress. Biomed Pharmacother 58: 39-46.

[261] Paglieri C, Bisbocci D, Caserta M, Rabbia F, Bertello C, Canadè A, Veglio F (2008) Hypertension and cognitive function. Clin Exp Hypertens 30: 701-710.

[262] Kivipelto M, Helkala EL, Laakso MP, Hänninen T, Hallikainen M, Alhainen K, Soininen H, Tuomilehto J, Nissinen A (2001) Midlife vascular risk factors and Alzheimer's disease in later life: longitudinal, population based study. BMJ 322: 1447-1451.

[263] Kehoe PG, Miners S, Love S (2009) Angiotensins in Alzheimer's disease - friend or foe? Trends Neurosci 32: 619-628.

[264] Takeda S, Sato N, Ogihara T, Morishita R (2008) The ennin-angiotensin system, hypertension and cognitive dysfunction in Alzheimer's disease: new therapeutic potential. Front Biosci 13: 2253-2265.

[265] Elias MF, D’Agostino RB, Elias PK, Wolf PA (1995) Neuropsychological test performance, cognitive functioning, blood pressure, and age: the Framingham Heart Study. Exp Aging Res 21: 369-391.

[266] Farmer ME, Kittner SJ, Abbott RD, Wolz MM, Wolf PA, White LR (1990) Longitudinally measured blood pressure, antihypertensive medication use, and cognitive performance: the Framingham Study. J Clin Epidemiol 43: 475-480.

[267] Elias MF, Wolf PA, D'Agostino RB, Cobb J, White LR (1993) Untreated blood pressure level is inversely related to cognitive functioning: the Framingham Study. Am J Epidemiol 138: 353-364.

[268] Poon IO (2008) Effects of antihypertensive drug treatment on the risk of dementia and cognitive impairment. Pharmacotherapy 28: 366-375. 
[269] Dickstein DL, Walsh J, Brautigam H, Stockton SD Jr, Gandy S, Hof PR (2010) Role of vascular risk factors and vascular dysfunction in Alzheimer's disease. Mt Sinai J Med 77: 82-102.

[270] Svatikova A, Wolk R, Shamsuzzaman AS, Kara T, Olson EJ, Somers VK (2003) Serum amyloid a in obstructive sleep apnea. Circulation 108: 1451-1454.

[271] Poitou C, Coupaye M, Laaban JP, Coussieu C, Bedel JF, Bouillot JL, Basdevant A, Clément K, Oppert JM (2006) Serum amyloid A and obstructive sleep apnea syndrome before and after surgically-induced weight loss in morbidly obese subjects. Obes Surg 16: 1475-1481.

[272] Wright JW, Harding JW (2010) The brain RAS and Alzheimer's disease. Exp Neurol 223: 326-333.

[273] Gentile MT, Poulet R, Di Pardo A, Cifelli G, Maffei A, Vecchione C, Passarelli F, Landolfi A, Carullo P, Lembo G (2009) $\beta$-amyloid deposition in brain is enhanced in mouse models of arterial hypertension. Neurobiol Aging 30: 222-228.

[274] Bloomfield SM, McKinney J, Smith L, Brisman J (2007) Reliability of S100B in predicting severity of central nervous system injury. Neurocrit Care 6: 121-138.

[275] Braga CW, Martinez D, Wofchuk S, Portela LV, Souza DO (2006) S100B and NSE serum levels in obstructive sleep apnea syndrome. Sleep Med 7, 431-435.

[276] Sonka K, Kelemen J, Kemlink D, Volná J, Pretl M, Zima T, Benakova H, Rambousek P, Foltán R, Donev F (2007) Evening and morning plasma levels of protein S100B in patients with obstructive sleep apnea. Neuro Endocrinol Lett 28: 575-579.

[277] Breteler MM (2000) Vascular involvement in cognitive decline and dementia. Epidemiologic evidence from the Rotterdam Study and the Rotterdam Scan Study. Ann N Y Acad Sci 903: 457-465.

[278] Devisser A, Yang C, Herring A, Martinez JA, Rosales-Hernandez A, Poliakov I, Ayer A, Garven A, Zaver S, Rincon N, Xu K, Tuor UI, Schmidt AM, Toth C (2011) Differential impact of diabetes and hypertension in the brain: adverse effects in grey matter. Neurobiol Dis 44: 161-173.

[279] Qiu C, Winblad B, Fratiglioni L (2005)The age-dependent relation of blood pressure to cognitive function and dementia. Lancet Neurol 4: 487-499.

[280] Razay G, Williams J, King E, Smith AD, Wilcock G (2009) Blood pressure, dementia and Alzheimer's disease: the OPTIMA longitudinal study. Dement Geriatr Cogn Disord 28: 70-74.

[281] Joas E, Bäckman K, Gustafson D, Ostling S, Waern M, Guo X, Skoog I (2012) Blood pressure trajectories from midlife to late life in relation to dementia in women followed for 37 years. Hypertension 59 : 796-801.

[282] Wirths O, Breyhan H, Marcello A, Cotel MC, Brück W, Bayer TA (2010) Inflammatory changes are tightly associated with neurodegeneration in the brain and spinal cord of the APP/PS1KI mouse model of Alzheimer's disease. Neurobiol Aging 31: 747-757.

[283] Desai AK (2011) Revitalizing the aged brain. Med Clin North Am 95: 463-475.

[284] Sachdev PS, Brodaty H, Reppermund S, Kochan NA, Trollor JN, Draper B, Slavin MJ (2010) The Sydney Memory and Ageing Study (MAS): methodology and baseline medical and neuropsychiatric characteristics of an elderly epidemiological non-demented cohort of Australians aged 70-90 years. Int Psychogeriatr 22: 1248-1264.

[285] Hohman TJ, Beason-Held LL, Resnick SM (2011) Cognitive complaints, depressive symptoms, and cognitive impairment: are they related? J Am Geriatr Soc 59: 1908-1912.

[286] Saunamäki T, Jehkonen M (2007) Depression and anxiety in obstructive sleep apnea syndrome: a review. Acta Neurol Scand 116: 277-288. 
[287] Choi NG, Dinitto DM (2011) Heavy/binge drinking and depressive symptoms in older adults: gender differences. Int J Geriatr Psychiatry 26: 860-868.

[288] Godbout JP, Moreau M, Lestage J, Chen J, Sparkman NL, O' Connor J, Castanon N, Kelley KW, Dantzer R, Johnson RW (2008) Aging exacerbates depressive-like behavior in mice in response to activation of the peripheral innate immune system. Neuropsychopharmacology 33: 2341-2351.

[289] Maes M, Kubera M, Obuchowiczwa E, Goehler L, Brzeszcz J (2011) Depression's multiple comorbidities explained by (neuro)inflammatory and oxidative \& nitrosative stress pathways. Neuro Endocrinol Lett 32: 7-24.

[290] Akiyama H, Meyer JS, Mortel KF, Terayama Y, Thornby JI, Konno S (1997) Normal human aging: factors contributing to cerebral atrophy. J Neurol Sci 152: 39-49.

[291] Shimada A (1999) Age-dependent cerebral atrophy and cognitive dysfunction in SAMP10 mice. Neurobiol Aging 20: 125-36.

[292] Clyburn EB, DiPette DJ (1995) Hypertension induced by drugs and other substances. Semin Nephrol 15: 72-86.

[293] Migliore L, Coppedè F (2009) Environmental-induced oxidative stress in neurodegenerative disorders and aging. Mutat Res 674: 73-84.

[294] Ogasawara K, Nakamura Y, Aleksic B, Yoshida K, Ando K, Iwata N, Kayukawa Y, Ozaki N (2011) Depression associated with alcohol intake and younger age in Japanese office workers: a case- control and a cohort study. J Affect Disord 128: 33-40.

[295] Tobe SW, Soberman H, Kiss A, Perkins N, Baker B (2006) The effect of alcohol and gender on ambulatory blood pressure: results from the Baseline Double Exposure study. Am J Hypertens 19: $136-139$.

[296] McFarlane SI, von Gizycki H, Salifu M, Deshmukh M, Manieram M, Gebreegziabher Y, Gliwa AA, Bordia S, Shah S, Sowers JR (2007) Alcohol consumption and blood pressure in the adult US population: assessment of gender-related effects. J Hypertens 25: 965-970.

[297] Estruch R, Nicolás JM, Salamero M, Aragón C, Sacanella E, Fernández-Solà J, Urbano-Márquez A (1997) Atrophy of the corpus callosum in chronic alcoholism. J Neurol Sci 146: 145-151.

[298] Teipel SJ, Bayer W, Alexander GE, Bokde AL, Zebuhr Y, Teichberg D, Müller-Spahn F, Schapiro MB, Möller HJ, Rapoport SI, Hampel H (2003) Regional pattern of hippocampus and corpus callosum atrophy in Alzheimer's disease in relation to dementia severity: evidence for early neocortical degeneration. Neurobiol Aging 24: 85-94.

[299] Teipel SJ, Bayer W, Alexander GE, Zebuhr Y, Teichberg D, Kulic L, Schapiro MB, Möller HJ, Rapoport SI, Hampel H(2002) Progression of corpus callosum atrophy in Alzheimer disease. Arch Neurol 59: 243248.

[300] Nicolás JM, Catafau AM, Estruch R, Lomeña FJ, Salamero M, Herranz R, Monforte R, Cardenal C, Urbano-Marquez A (1993) Regional cerebral blood flow-SPECT in chronic alcoholism: relation to neuropsychological testing. J Nucl Med 34: 1452-1459.

[301] Williams-Hemby L, Porrino LJ (1994) Low and moderate doses of ethanol produce distinct patterns of cerebral metabolic changes in rats. Alcohol Clin Exp Res 18: 982-988.

[302] Christie IC, Price J, Edwards L, Muldoon M, Meltzer CC, Jennings JR (2008) Alcohol consumption and cerebral blood flow among older adults. Alcohol 42: 269-275.

[303] Pach D, Hubalewska-Dydejczyk A, Szurkowska M, Kamenczak A, Targosz D, Gawlikowski T, Huszno B, Głowa B (2007) Evaluation of regional cerebral blood flow using 99mTc-ECD SPECT in ethanol dependent patients: pilot study. Przegl Lek 64: 204-207. 
[304] Talukder MA, Johnson WM, Varadharaj S, Lian J, Kearns PN, El-Mahdy MA, Liu X, Zweier JL (2011) Chronic cigarette smoking causes hypertension, increased oxidative stress, impaired NO bioavailability, endothelial dysfunction, and cardiac remodeling in mice. Am J Physiol Heart Circ Physiol 300: H388-H396.

[305] Halterman MW , Miller CC , Federoff HJ (1999) Hypoxia-inducible factor-1alpha mediates hypoxiainduced delayed neuronal death that involves p53. J Neurosci 19: 6818-6824.

[306] Pulsinelli WA, Brierley JB , Plum F (1982) Temporal profile of neuronal damage in a model of transient forebrain ischemia. Ann Neurol 11: 491-498.

[307] Chen J , Nagayama T, Jin K, Stetler RA, Zhu RL, Graham SH, Simon RP (1998) Induction of caspase-3-like protease may mediate delayed neuronal death in the hippocampus after transient cerebral ischemia. J Neurosci 18: 4914-4928.

[308] Rabinovici GD, Jagust WJ (2009)Amyloid imaging in aging and dementia: testing the amyloid hypothesis in vivo. Behav Neurol 21: 117-28.

[309] Sadowski M, Pankiewicz J, Scholtzova H, Li YS, Quartermain D, Duff K, Wisniewski T (2004) Links between the pathology of Alzheimer's disease and vascular dementia. Neurochem Res 29: 1257-1266.

[310] Austin BP, Nair VA, Meier TB, Xu G, Rowley HA, Carlsson CM, Johnson SC, Prabhakaran V (2011) Effects of hypoperfusion in Alzheimer's disease. J Alzheimers Dis 26 Suppl 3: 123-133.

[311] Sun X, He G, Qing H, Zhou W, Dobie F, Cai F, Staufenbiel M, Huang LE, Song W (2006) Hypoxia facilitates Alzheimer's disease pathogenesis by up-regulating BACE1 gene expression. Proc Natl Acad Sci U S A 103: 18727-18732.

[312] Anglade P, Vyas S, Hirsch EC, Agid Y (1997) Apoptosis in dopaminergic neurons of the human substantia nigra during normal aging. Histol Histopathol 12: 603-610.

[313] Zhang F, Yin W, Chen J (2004) Apoptosis in cerebral ischemia: executional and regulatory ennin ng mechanisms. Neurol Res 26: 835-845.

[314] Gilles FH (1969) Hypotensive brain stem necrosis: selective symmetrical necrosis of tegmental neuronal aggregates following cardiac arrest. Arch Pathol 88: 32-41.

[315] Revesz T, Geddes JF (1988) Symmetrical columnar necrosis of the basal ganglia and brain stem in an adult following cardiac arrest. Clin Neuropathol 6: 294-298.

[316] De Caro R, Parenti A, Montisci M, Guidolin D, Macchi V (2003) Symmetrical selective neuronal necrosis in solitary tract nuclei. Int J Legal Med 117: 253-254.

[317] Parenti A, Macchi V, Snenghi R, Porzionato A, Scaravilli T, Ferrara SD, De Caro R (2005) Selective stroke of the solitary tract nuclei in two cases of central sleep apnoea. Clin Neuropathol 24: 239-246.

[318] Gustafson D, Lissner L, Bengtsson C, Björkelund C, Skoog I (2004) A 24-year follow-up of body mass index and cerebral atrophy. Neurology 63: 1876-1881.

[319] Kivipelto M, Ngandu T, Fratiglioni L, Viitanen M, Kåreholt I, Winblad B, Helkala EL, Tuomilehto J, Soininen $\mathrm{H}$, Nissinen A (2005) Obesity and vascular risk factors at midlife and the risk of dementia and Alzheimer disease. Arch Neurol 62: 1556-1560.

[320] Rosengren A, Skoog I, Gustafson D, Wilhelmsen L (2005) Body mass index, other cardiovascular risk factors, and hospitalization for dementia. Arch Intern Med 165: 321-326.

[321] Whitmer RA, Gunderson EP, Barrett-Connor E (2005) Obesity in middle age and future risk of dementia: A 27 year longitudinal population based study. BMJ 330: 1360.

[322] Zanni MV, Stanley TL, Makimura H, Chen CY, Grinspoon SK (2010) Effects of TNF-alpha antagonism on E-selectin in obese subjects with metabolic dysregulation. Clin Endocrinol (Oxf) 73: 48-54. 
[323] lannone F, Lapadula G (2010) Obesity and inflammation-targets for OA therapy. Curr Drug Targets 11: 586-98.

[324] Walther K, Birdsill AC, Glisky EL, Ryan L (2010) Structural brain differences and cognitive functioning related to body mass index in older females. Hum Brain Mapp 31: 1052-1064.

[325] Raji CA, Ho AJ, Parikshak NN, Becker JT, Lopez OL, Kuller LH, Hua X, Leow AD, Toga AW, Thompson PM (2010) Brain structure and obesity. Hum Brain Mapp 31: 353-364.

[326] Luchsinger JA, Mayeux (2007) R Adiposity and Alzheimer's disease. Curr. Alzheimer Res 4: 127-134.

[327] Erol A (2008) An integrated and unifying hypothesis for the metabolic basis of sporadic Alzheimer's disease. J. Alzheimers Dis 13: 241-253.

[328] Ho L, Qin W, Pompl PN, Xiang Z, Wang J, Zhao Z, Peng Y, Cambareri G, Rocher A, Mobbs CV, Hof PR, Pasinetti GM (2004) Diet-induced insulin resistance promotes amyloidosis in a transgenic mouse model of Alzheimer's disease. FASEB J 18: 902-904.

[329] Julien C, Tremblay C, Phivilay A, Berthiaume L, Emond V, Julien P, Calon F (2010) High-fat diet aggravates amyloid-beta and tau pathologies in the 3xTg-AD mouse model. Neurobiol Aging 31: 15161531.

[330] T. Wyss-Coray (2006) Inflammation in Alzheimer disease: driving force, bystander or beneficial response? Nat. Med 12: 1005-1015.

[331] Tan J, Town T, Crawford F, Mori T, DelleDonne A, Crescentini R, Obregon D, Flavell RA, Mullan MJ (2002) Role of CD40 ligand in amyloidosis in transgenic Alzheimer's mice. Nat Neurosci 5: 1288-1293.

[332] Kitazawa M, Oddo S, Yamasaki TR, Green KN, LaFerla FM (2005) Lipopolysaccharide-induced inflammation exacerbates tau pathology by a cyclin-dependent kinase 5-mediated pathway in a transgenic model of Alzheimer's disease. J. Neurosci 25: 8843-8853.

[333] Luchsinger JA, Reitz C, Patel B, Tang MX, Manly JJ, Mayeux R (2007) Relation of diabetes to mild cognitive impairment. Arch Neurol 64: 570-575.

[334] Takeda S, Sato N, Rakugi H, Morishita R (2011) Molecular mechanisms linking diabetes mellitus and Alzheimer disease: beta-amyloid peptide, insulin signaling, and neuronal function. Mol Biosyst 7: 1822-1827.

[335] Strachan MW, Reynolds RM, Marioni RE, Price JF (2011) Cognitive function, dementia and type 2 diabetes mellitus in the elderly. Nat Rev Endocrinol 7: 108-114.

[336] Hölscher C (2011) Diabetes as a risk factor for Alzheimer's disease: insulin ennin ng impairment in the brain as an alternative model of Alzheimer's disease. Biochem Soc Trans 39: 891-897.

[337] Murakami K, Yokoyama S, Murata N, Ozawa Y, Irie K, Shirasawa T, Shimizu T (2011) Insulin receptor mutation results in insulin resistance and hyperinsulinemia but does not exacerbate Alzheimer's-like phenotypes in mice. Biochem Biophys Res Commun 409: 34-39.

[338] Harsch IA, Hahn EG, Konturek PC (2005) Insulin resistance and other metabolic aspects of the obstructive sleep apnea syndrome. Med Sci Monit 11: RA70-RA75.

[339] Makino S, Handa H, Suzukawa K, Fujiwara M, Nakamura M, Muraoka S, Takasago I, Tanaka Y, Hashimoto K, Sugimoto T (2006) Obstructive sleep apnoea syndrome, plasma adiponectin levels, and insulin resistance. Clin Endocrinol (Oxf) 64: 12-19.

[340] Steiropoulos P, Papanas N, Nena E, Tsara V, Fitili C, Tzouvelekis A, Christaki P, Maltezos E, Bouros D (2009) Markers of glycemic control and insulin resistance in non-diabetic patients with Obstructive Sleep Apnea Hypopnea Syndrome: does adherence to CPAP treatment improve glycemic control? Sleep Med 10: 887-891. 
[341] Bonsignore MR, Esquinas C, Barceló A, Sanchez-de-la-Torre M, Paternó A, Duran-Cantolla J, Marín JM, Barbé F (2011) Metabolic syndrome, insulin resistance and sleepiness in real-life obstructive sleep apnoea. Eur Respir J Nov 10. [Epub ahead of print].

[342] Deboer MD, Mendoza JP, Liu L, Ford G, Yu PL, Gaston BM (2012) Increased systemic inflammation overnight correlates with insulin resistance among children evaluated for obstructive sleep apnea. Sleep Breath 16: 349-354.

[343] Yang D, Liu Z, Yang H, Luo Q (2012) Effects of continuous positive airway pressure on glycemic control and insulin resistance in patients with obstructive sleep apnea: a meta-analysis. Sleep Breath Mar 13. [Epub ahead of print].

[344] Moroz N, Tong M, Longato L, Xu H, de la Monte SM (2008) Limited Alzheimer-type neurodegeneration in experimental obesity and type 2 diabetes mellitus. J Alzheimers Dis 15: 29-44.

[345] Correia SC, Santos RX, Perry G, Zhu X, Moreira PI, Smith MA (2011) Insulin-resistant brain state: the culprit in sporadic Alzheimer's disease? Ageing Res Rev 10: 264-273.

[346] Moreira PI, Carvalho C, Zhu X, Smith MA, Perry G (2010) Mitochondrial dysfunction is a trigger of Alzheimer's disease pathophysiology. Biochim Biophys Acta 1802: 2-10.

[347] Horan MP, Pichaud N, Ballard JW (2012) Review: Quantifying Mitochondrial Dysfunction in Complex Diseases of Aging. J Gerontol A Biol Sci Med Sci Mar 29. [Epub ahead of print].

[348] Scaglia F (2010) The role of mitochondrial dysfunction in psychiatric disease. Dev Disabil Res Rev 16: 136-143.

[349] Kagan VE, Tyurina YY, Bayir H, Chu CT, Kapralov AA, Vlasova II, Belikova NA, Tyurin VA, Amoscato A, Epperly M, Greenberger J, Dekosky S, Shvedova AA, Jiang J (2006) The "pro-apoptotic genies" get out of mitochondria: oxidative lipidomics and redox activity of cytochrome c/cardiolipin complexes. Chem Biol Interact 163: 15-28.

[350] Yin H, Zhu M (2012) Free Radical Oxidation of Cardiolipin: Chemical Mechanisms, Detection, and Implication in Apoptosis, Mitochondrial Dysfunction, and Human Diseases. Free Radic Res Apr 3. [Epub ahead of print].

[351] Chakrabarti S, Munshi S, Banerjee K, Thakurta IG, Sinha M, Bagh MB (2011) Mitochondrial Dysfunction during Brain Aging: Role of Oxidative Stress and Modulation by Antioxidant Supplementation. Aging Dis 2: 242-256.

[352] Lloret A, Buj J, Badia MC, Sastre J, Morera J, Viña J(2007) Obstructive sleep apnea: arterial oxygen desaturation coincides with increases in systemic oxidative stress markers measured with continuous monitoring. Free Radic Biol Med 42: 893-894.

[353] Eckert A, Schmitt K, Götz J (2011) Mitochondrial dysfunction - the beginning of the end in Alzheimer's disease? Separate and synergistic modes of tau and amyloid- $\beta$ toxicity. Alzheimers Res Ther 3: 15.

[354] Lezi E, Swerdlow RH (2012) Mitochondria in neurodegeneration. Adv Exp Med Biol 942: 269-286.

[355] Trushina E, Nemutlu E, Zhang S, Christensen T, Camp J, Mesa J, Siddiqui A, Tamura Y, Sesaki H, Wengenack TM, Dzeja PP, Poduslo JF (2012) Defects in mitochondrial dynamics and metabolomic signatures of evolving energetic stress in mouse models of familial Alzheimer's disease. PloS One 7: e32737.

[356] Karbowski M, Neutzner A (2012) Neurodegeneration as a consequence of failed mitochondrial maintenance. Acta Neuropathol 123: 157-171.

[357] Aliev G, Palacios HH, Walrafen B, Lipsitt AE, Obrenovich ME, Morales L (2009) Brain mitochondria as a primary target in the development of treatment strategies for Alzheimer disease. Int J Biochem Cell Biol 41: $1989-2004$. 
[358] Wang Y, Zhang SX, Gozal D (2010) Reactive oxygen species and the brain in sleep apnea. Respir Physiol Neurobiol 174: 307-316.

[359] Shi Q, Gibson GE (2007) Oxidative stress and transcriptional regulation in Alzheimer disease. Alzheimer Dis Assoc Disord 21: 276-291.

[360] Ferrer I, Planas AM (2003) Signaling of cell death and cell survival following focal cerebral ischemia: life and death struggle in the penumbra. J Neuropathol Exp Neurol 62: 329-339.

[361] Kim GS, Jung JE, Narasimhan P, Sakata H, Yoshioka H, Song YS, Okami N, Chan PH (2011) Release of mitochondrial apoptogenic factors and cell death are mediated by CK2 and NADPH oxidase. $J$ Cereb Blood Flow Metab 32: 720-730.

[362] Ferreira IL, Resende R, Ferreiro E, Rego AC, Pereira CF (2010) Multiple defects in energy metabolism in Alzheimer's disease. Curr Drug Targets 11: 1193-1206.

[363] Fung SJ, Xi MC, Zhang JH, Sampogna S, Yamuy J, Morales FR, Chase MH (2007) Apnea promotes glutamate-induced excitotoxicity in hippocampal neurons. Brain Res 1179: 42-50.

[364] Xie SX, Libon DJ, Wang X, Massimo L, Moore P, Vesely L, Khan A, Chatterjee A, Coslett HB, Hurtig HI, Liang TW, Grossman M (2010) Longitudinal patterns of semantic and episodic memory in frontotemporal lobar degeneration and Alzheimer's disease. J Int Neuropsychol Soc 16: 278-286.

[365] Gozal D, Daniel J.M. Dohanich G.P (2001) Behavioral and anatomical correlates ofchronic episodic hypoxia during sleep in the rat. J Neurosci 21: 2442-2450.

[366] Gozal D, Row BW, Kheirandish L, Liu R, Guo SZ, Qiang F, Brittian KR (2003) Increased susceptibility to intermittent hypoxia in aging rats: changes in proteasomal activity, neuronal apoptosis and spatial function. J Neurochem 86: 1545-1552.

[367] Goldbart, B.W. Row, L. Kheirandish, A. Schurr, E. Gozal, S.Z. Guo, R.S. Payne, Z. Cheng, K. Brittian, D. Gozal (2003) Intermittent hypoxic exposure during light phase induces changes in cAMP response element binding protein activity in the rat CA1 hippocampal region: water maze performance correlates. Neuroscience 122: 583-590.

[368] Ward CP, McCoy JG, McKenna JT, Connolly NP, McCarley RW, Strecker RE (2009) Spatial learning and memory deficits following exposure to $24 \mathrm{~h}$ of sleep fragmentation or intermittent hypoxia in a rat model of obstructive sleep apnea. Brain Res 1294: 128-137.

[369] Row BW, Liu R, Xu W, Kheirandish L, Gozal D (2003) Intermittent hypoxia is associated with oxidative stress and spatial learning deficits in the rat. Am J Respir Crit Care Med 167: 1548-1553.

[370] Li RC, Row BW, Kheirandish L, Brittian KR, Gozal E, Guo SZ, Sachleben LR Jr, Gozal D (2004) Nitric oxide synthase and intermittent hypoxia-induced spatial learning deficits in the rat. Neurobiol Dis 17: 44-53.

[371] Li RC, Row BW, Gozal E, Kheirandish L, Fan Q, Brittian KR, Guo SZ, Sachleben LR Jr, Gozal D (2003) Cyclooxygenase 2 and intermittent hypoxia-induced spatial deficits in the rat. Am J Respir Crit Care Med 168: 469-475.

[372] Bourgeat P, Chételat G, Villemagne VL, Fripp J, Raniga P, Pike K, Acosta O, Szoeke C, Ourselin S, Ames D, Ellis KA, Martins RN, Masters CL, Rowe CC, Salvado O (2010) Beta-amyloid burden in the temporal neocortex is related to hippocampal atrophy in elderly subjects without dementia. Neurology 74 : 121-127.

[373] Dai W, Lopez OL, Carmichael OT, Becker JT, Kuller LH, Gach HM (2008) Abnormal regional cerebral blood flow in cognitively normal elderly subjects with hypertension. Stroke 39: 349-354

[374] Korf ES, White LR, Scheltens P, Launer LJ (2004) Midlife blood pressure and the risk of hippocampal atrophy: the Honolulu Asia Aging Study. Hypertension 44: 29-34.

[375] Wiseman RM, Saxby BK, Burton EJ, Barber R, Ford GA, O'Brien JT (2004) Hippocampal atrophy, whole brain volume, and white matter lesions in older hypertensive subjects. Neurology 63: 1892-1897. 
[376] Quu C, Winblad B, Fratiglioni L (2005) The age-dependent relation of blood pressure to cognitive function and dementia. Lancet Neurol 4: 487-499.

[377] Razay G, Williams J, King E, Smith AD, Wilcock G (2009) Blood pressure, dementia and Alzheimer's disease: the OPTIMA longitudinal study. Dement Geriatr Cogn Disord 28: 70-74.

[378] Espinosa-Oliva AM, de Pablos RM, Villarán RF, Argüelles S, Venero JL, Machado A, Cano J (2011) Stress is critical for LPS-induced activation of microglia and damage in the rat hippocampus. Neurobiol Aging 32: 85-102.

[379] Tagliari B, Tagliari AP, Schmitz F, da Cunha AA, Dalmaz C, Wyse AT (2011) Chronic variable stress alters inflammatory and cholinergic parameters in hippocampus of rats. Neurochem Res 36, 487-93.

[380] Castle, M, Comoli E, and Loewy AD (2005) Autonomic brainstem nuclei are linked to the hippocampus. Neuroscience 134: 657-669.

[381] Loewy, AD (1998) Viruses as transneuronal tracers for defining neural circuits. Neurosci Biobehav Rev 22: 679-684.

[382] Dong HW, Petrovich GD, Watts AG, Swanson LW (2001) Basic organization of projections from the oval and fusiform nuclei of the bed nuclei of the stria terminalis in adult rat brain. J Comp Neurol 436: 430455.

[383] Loy R, Koziell DA, Lindsey JD, Moore, RY (1980) Noradrenergic innervation of the adult rat hippocampal formation. J Comp Neurol 189: 699-710.

[384] Rye DB, Wainer BH, Mesulam MM, Mufson EJ, Saper, CB (1984) Cortical projections arising from the basal forebrain: a study of cholinergic and noncholinergic components employing combined retrograde tracing and immunohistochemical localization of choline acetyltransferase. Neuroscience 13: 627-643.

[385] Vgontzas AN, Bixler EO, Chrousos GP (2005) Sleep apnea is a manifestation of the metabolic syndrome. Sleep Med Rev 9:211-224

[386] Vgontzas AN (2008) Does obesity play a major role in the pathogenesis of sleep apnoea and its associated manifestations via inflammation, visceral adiposity, and insulin resistance? Arch Physiol Biochem 114:211-223

[387] Carneiro G, Togeiro SM, Ribeiro-Filho FF, Truksinas E, Ribeiro AB, Zanella MT, Tufik S (2009) Continuous positive airway pressure therapy improves hypoadiponectinemia in severe obese men with obstructive sleep apnea without changes in insulin resistance. Metab Syndr Relat Disord 7:537-542.

[388] Mokhlesi B, Scoccia B, Mazzone T, Sam S Risk of obstructive sleep apnea in obese and nonobese women with polycystic ovary syndrome and healthy reproductively normal women. Fertil Steril 97:786-791

[389] Nitsche K, Ehrmann DA (2010) Obstructive sleep apnea and metabolic dysfunction in polycystic ovary syndrome. Best Pract Res Clin Endocrinol Metab 24:717-730.

[390] Lin O, Zhang X, Chen G, Huang D, Din H and Tang A (2012) Obstructive sleep apnea syndrome is associated with some components of metabolic syndrome in nonobese adults. Sleep Breath 16: 571-578.

[391] Tasali E, Van Cauter E, Hoffman L, Ehrmann DA (2008) Impact of obstructive sleep apnea on insulin resistance and glucose tolerance in women with polycystic ovary syndrome. J Clin Endocrinol Metab 93:3878-3884.

[392] Liu A, Kushida CA, Reaven GM (2012) Risk for obstructive sleep apnea in obese, nondiabetic adults varies with insulin resistance status. Sleep Breath Apr 7. [Epub ahead of print]

[393] Moroz N, Tong M, Longato L, Xu H, de la Monte SM (2008) Limited Alzheimer-type neurodegeneration in experimental obesity and type 2 diabetes mellitus. J Alzheimers Dis 15:29-44. 
[394] Musicco M, Palmer K, Salamone G, Lupo F, Perri R, Mosti S, Spalletta G, di lulio F, Pettenati C, Cravello L, Caltagirone C (2009) Predictors of progression of cognitive decline in Alzheimer's disease: the role of vascular and sociodemographic factors. J Neurol 256:1288-95.

[395] Dong YF, Kataoka K, Toyama K, Sueta D, Koibuchi N, Yamamoto E, Yata K, Tomimoto H, Ogawa H, Kim-Mitsuyama S (2011) Attenuation of brain damage and cognitive impairment by direct ennin inhibition in mice with chronic cerebral hypoperfusion. Hypertension 58:635-642.

[396] Inaba S, Iwai M, Furuno M, Tomono Y, Kanno H, Senba I, Okayama H, Mogi M, Higaki J, Horiuchi M (2009) Continuous activation of ennin-angiotensin system impairs cognitive function in ennin/angiotensinogen transgenic mice. Hypertension 53:356-362.

[397] Inaba S, Iwai M, Tomono Y, Senba I, Furuno M, Kanno H, Okayama H, Mogi M, Higaki J, Horiuchi M (2009) Exaggeration of focal cerebral ischemia in transgenic mice carrying human Renin and human angiotensinogen genes. Stroke 40:597-603

[398] Díaz-Ruiz C, Wang J, Ksiezak-Reding H, Ho L, Qian X, Humala N, Thomas S, Martínez-Martín P, Pasinetti GM (2009) Role of Hypertension in Aggravating Abeta Neuropathology of AD Type and TauMediated Motor Impairment. Cardiovasc Psychiatry Neurol 2009:107286.

[399] Sun X, He G, Qing H, Zhou W, Dobie F, Cai F, Staufenbiel M, Huang LE, Song W (2006) Hypoxia facilitates Alzheimer's disease pathogenesis by up-regulating BACE1 gene expression. Proc. Natl. Acad. Sci. U S A 103 :18727-18732.

[400] Zhang X, Zhou K, Wang R, Cui J, Lipton SA, Liao FF, Xu H, Zhang YW (2007) Hypoxia-inducible factor 1alpha (HIF-1alpha)-mediated hypoxia increases BACE1 expression and beta-amyloid generation. J. Biol. Chem 282:10873-10880.

[401] Rosenberg PB, Drye LT, Martin BK, Frangakis C, Mintzer JE, Weintraub D, Porsteinsson AP, Schneider LS, Rabins PV, Munro CA, Meinert CL, Lyketsos CG (2010) Sertraline for the Treatment of Depression in Alzheimer Disease. Am J Geriatr Psychiatry. 18:136-145.

[402] O'Collins VE, Macleod MR, Donnan GA, Horky LL, van der Worp BH, Howells DW $(2006) 1,026$ experimental treatments in acute stroke. Ann Neurol 59:467-477.

[403] DeGracia DJ (2010) Towards a dynamical network view of brain ischemia and reperfusion. Part IV: Additional considerations. J Exp Stroke Transl Med 3:104-114

[404] Huang S, Wikswo J (2006) Dimensions of systems biology. Rev Physiol Biochem Pharmacol 157:81104

[405] Tyson JJ, Chen K, Novak B (2001) Network dynamics and cell physiology. Nat Rev Mol Cell Biol 2:908-916

\section{$\underline{\text { SEE Fiqure } 1 \text { Below }}$}




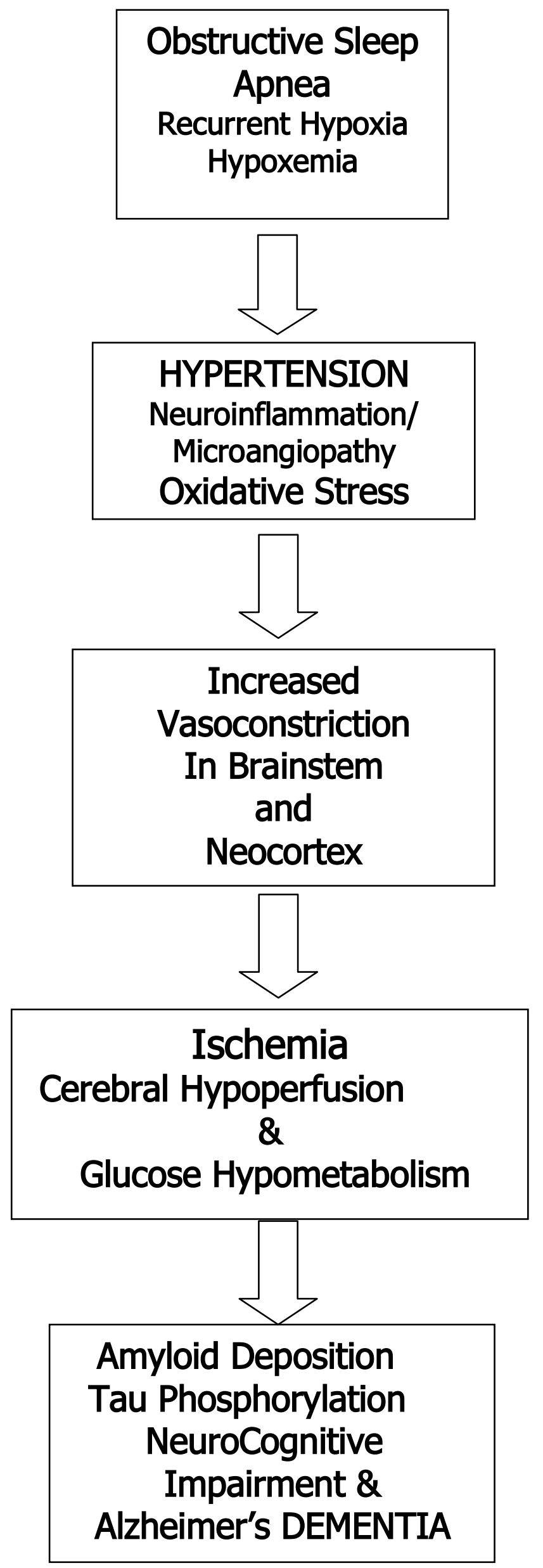


Fig. 1. Simplified schematic representation showing the fundamental role of Apnea and hypoxia in promotong hypertension, neuroinflammation, ischemia, hypoperfusion, and glucose hypometabolism; all of these risk factors promote amyloid deposition and tau hyperphosphorylation. In the wake of decreased oxygen and glucose metabolism, there is depression in energy and high phosphate compound ATP, promoting neuronal injury/apoptosis, and degeneration, leading to cognitive impairment and dementia. 


\section{University Library}

\section{- M M N E R VA A gateway to Melbourne's research publications}

Minerva Access is the Institutional Repository of The University of Melbourne

Author/s:

Daulatzai, MA

Title:

Quintessential Risk Factors: Their Role in Promoting Cognitive Dysfunction and Alzheimer's Disease

Date:

2012-12-01

Citation:

Daulatzai, M. A. (2012). Quintessential Risk Factors: Their Role in Promoting Cognitive Dysfunction and Alzheimer's Disease. NEUROCHEMICAL RESEARCH, 37 (12), pp.2627-2658. https://doi.org/10.1007/s11064-012-0854-6.

Persistent Link:

http://hdl.handle.net/11343/282776 